Anneliese Meis, S.Sp.S.

Profesora de la Facultad de Teología

Pontificia Universidad Católica de Chile

\title{
Razón y amor en la teología medieval incipiente: Aproximación desde la confluencia de las fuentes griegas y latinas
}

Desde siempre el ser humano resulta un enigma para sí mismo y los demás, situación que no se soluciona, sino se intensifica pese a los innumerables intentos de penetrarlo racionalmente, tal como lo atestigua la historia del pensamiento humano (1). Ello explica el hecho que la pregunta acerca de qué es el hombre haya sido declarada por Kant una pregunta originaria. En efecto, el problema de volver al origen es provocativo y produce un cambio significativo en el enfoque de la pregunta en el que se produce un desplazamiento del qué al cómo. En virtud de este cambio la inquietud ontológica se integra en la epistemológica, enfatizando por encima de la substancia, la relación, sin desmedro de aquella (2).

Emerge así una dualidad básica, propia del ritmo del ser, que se articula en la polaridad, cuando esta distingue polos opuestos, sin separar ni confundirlos (3). Entre las múltiples expresiones de tal polaridad, la del conocimiento y el amor resulta especialmente enigmática (4). Dicha polaridad explicita dos capacidades básicas del ser humano, que las ciencias exactas tienden a separar nítidamente por exclusión, dando preferencia a las "ideas claras y distintas", mientras exponentes

(1) El presente estudio síntetiza los primeros resultados obtenidos por la investigación del Proyecto Fondecyt 1020470: El enigma del hombre a la luz de la confluencia de las fuentes griegas y latinas en Guillermo de St.Thierry y trasmitidos a nivel de postgrado de Licenciatura en Teología Dogmática, Facultad de Teología durante el primer semestre de 2002. Va anexado el Proyecto Especial DIPUC 2002-2003: "Racionalidad ardiente”: Aproximación al problema razón y amor en la obra Scivias de Hildegard von Bingen y será completado por la Cooperación científica Internacional 2003-2004 que abordará, bajo la dirección del Profesor H. Drobner/Alemania, "El Problema de las fuentes: su recepeción patrística medieval”.

(2) Cf. MARION J. L., Etant donné. Essai d’une phénoménlogie de la donation, 2.ed., Paris 1998; ULRICH F., HOMO ABYSSUS. Das Wagnis der Seinsfrage, Einsiedeln 1961.

(3) Se entiende por polaridad, el hecho de que poseo plenamente el ser sin agotarlo, tal como reflexiona Hans Urs von Balthasar a lo largo de su extensa obra. Cf. Intento de resumir mi pensamiento Communio 10 (1988) 284-288.

(4) Cf. KERN U., Liebe als Erkenntnis und Konstruktion von Wirklichkeit. "Erinnerung" an ein stets aktuales Erkenntnispotential (Theologische Bibliothek Töpelmann, 109) Berlin-New York 2001, 295 pp. 
destacados de la Filosofía actual demuestran que razón y amor están uno en el otro, y como tales se complementan.

En efecto, siguiendo a E. Husserl y M. Heidegger (5), M. Scheler cuestiona la comprensión budista e hinduista del problema conocimiento y amor, a la vez que acusa de desvíos a la concepción cristiana, al resaltar la dimensión agápica del amor personal, en la que culmina todo conocimiento (6). M. Merleau Ponty, por su parte, abre el acceso a una "racionalidad sentida" y "emocional" (7), que J. L. Marion completa con sus afinados análisis de la "carne" e "intencionalidad" (8). Tradiciones antiguas ya habían discutido la importancia del eros para el conocimiento (9) y la concreción del ágape bíblico (10), del mismo modo como hoy se ahonda en el estudio de las experiencias humanas, desde la sonrisa de la madre para con su hijo hasta los éxtasis de los grandes "místicos" (11), en busca de mayor claridad del problema razón y amor (12).

Si se pretende delimitar dicho problema en el siglo XII, cabe prestar atención a una simultaneidad paradójica entre los procesos de racionalización y mística, no carente de fuertes tensiones (13). Pero mientras todo el problema del conocimiento gira en torno a la pregunta acerca del fundamento (divino) que hace inteligible lo que existe e ilumina el intelecto humano (14), el problema del amor es abordado en sus aspectos más variados (15), a partir de una oposición entre la concepción física y extática (16). De todos modos, tanto la emergente tendencia racionalista como la mística se deben comprender en un contexto más amplio (17).

(5) HEIDEGGER M., Was heisst Denken, en Vorträge und Aufsätze, Pfullingen 1954, 129-143.

(6) SCHELER M., Liebe und Erkenntnis, en, M. SCHELER, Von der Ganzheit des Menschen, Ausgewählte Schriften, hg. M. S.FRINGS, Bonn 1991, 73-94; cf.J. DISSE, Liebe und Erkenntnis. Zur Geistmetaphysik Hans Urs von Balthasars, MThZ (1999) 219-227.

(7) CONTRERAS J.P., Maurice Merleau-Ponty, La dialéctica como silencio y práctica encarnada, MENSAJE 487 (2000) 106-111; Cf. ROSENBERGER M., Mit beherzter Vernunft: Fühlen und Denken in ihrer Bedeutung für das sittliche Urteil, MTZ 53 (2002) 59-72.

(8) MARION J. L., La intencionalidad del amor, en homenaje a Emmanuel Lévinas, en Prolegómenos a la Caridad (Colección Esprit, con la colaboración del Instituto Emmanuel Mounier) Madrid 1993, 173 pp; La paradoja de la persona, MENSAJE 486 (2000) 21-27.

(9) Cf. ANDIA Y. de, "Eros" y "ágape": la divina pasión de amor, COMMUNIO 16 (1994) 418-438.

(10) CODA P., El Agape como gracia y libertad en la raíz de la Teología y la práxis de los cristianos, Madrid-Buenos Aires-Santafé de Bogotá, Montevideo-Santiago 1996, pp.190

(11) Cf. H. URS BALTHASAR, Gloria V, Madrid 1988, 563-575;. Cf. SHERWIN M.S., Saint Thomas, Helen Keller, et la rationalité de l’amour, NOVA ET VETERA (2002) 21-32.

(12) Cabe recordar el mismo aporte de Heidegger, M. Weber, y sobre todo, M. Scheler, pero también la dimensión carismática -Pablo- del "don de la razón” -Gregorio de Nisa- Cf. KERN U., Zum Charisma der Rationalität, TL 112 (1987) 865-881.

(13) Cf. LANGER O.; Affekt und Ratio, en C. KASPER; K. SCHREINER (Hgg), Zisterziensische Spiritualität: Theologische Grundlagen, St. Ottilien 1994, 33-52.

(14) Cf. ENGELHARDT P., Erkenntnis, LM, 2, 2150 s.

(15) WENNER F., Charite, Le XII siecle, DSp 3, 570-571. cf. MARVAL P., Liebe V, TRE 21 (1991) $146-152$

(16) Cf. LANDGRAF A, Charité, DSp 3, 579; Cf. OESTERREICH P.L., Thomas von Aquins Lehre von der Liebe als menschliche Grundleidenschaft, ThPh 66 (1991) 90-97: el autor subraya la mutua inhaesio. cf. p.92.

(17) CHENU M.D., La Théologie au douziéme Siécle (Etudes de Philosophie Médievale, 45) Paris 1957; Cf. ROUGEMONT D. de, El amor y Occidente, 7. ed., Barcelona 1997; BALADIER C., La philosophie de 1' amour et du désir au Moyen Age, Nouvelle Revue de Pscychoanalyse: Aimer etre aimé 49 (1994) 149-163; GUTH K., Zum Verhältnis von Exegese und Philosophie im 
El presente estudio escoge un período poco conocido, pero de gran envergadura teológica y excepcionalmente sensible al problema razón y amor (18). En el siglo XII se va gestando la subjetividad moderna, de tanta relevancia para la teología, pero, sobre todo, se produce aquella confluencia de fuentes latinas y griegas, que como problema requiere máxima atención, ya que su recepción patrística medieval es vital para la búsqueda de la verdad a través de la ciencia. En efecto, "la fuente garantiza la originalidad de un pensamiento, en la medida en que ella se renueva por una transformación significativa" (19). Lo que mejor se perfila a partir de fuentes latinas son aquellas facetas más nítidas del problema razón y amor, su índole personal, concreta y práctica. El pensamiento griego, por su parte, complementará esta nitidez con el característico desborde del ser con respecto al pensar. De todos modos, lo que importa es la confluencia de las fuentes en una obra determinada de un autor medieval.

Pretendemos estudiar siete autores que se remontan al siglo XII -Hildegard von Bingen (20), Guillermo de St.Thierry (21), Ricardo de San Víctor (22), precedidos por Gregorio Magno (23), Juan Escoto Eriúgena (24) y Anselmo de Canterbury (25) - y complementados por Buenaventura (26). La elección de estos autores -sin ser exhaustiva- no ha sido casual, pues nos ha permitido seguir de cerca la articulación del problema, su contextualización y las soluciones novedosas, a que han dado lugar, de gran riqueza antropológica teológica. Cabe preguntar si lo que ellos evidencian es una exclusión de la razón con respecto al amor o su contrario, una complementación o una identificación, ¿una compenetración y perijoresis? La mejor intelección del problema razón y amor, ¿requiere de un a priori filosófico, teológico o trinitario? Estas preguntas orientan la presente investigación, a modo de preguntas metódicas.

Zeitalter der Frühscholastik, RTAM 38( 1971) 121-136; SCHMIDT M.A. Zur Trinitätslehre der Frühscholastik.Versuch einer problemgeschichtlichen Orientierung, TZ 40 (1984) 181-192.; LAFONT G., Histoire théolgique de 1’Eglise catholique et formes de la théologie, Paris 1994.

(18) LECLERQ J., Initiation aux auteurs monastiques du Moyen Age. Le amour des lettres \&le desir de Dieu, 2.ed., Paris 1968.

(19) Cf. BEIERWALTES W., Eriugena.Studien zu seinen Quellen. Vorträge des Internationalen Eriugena-Colloquiums. Freiburg im Breisgau. 27-30.August 1979 (Abhandlungen der Heidelberger Akademie der Wissenschaften) Heidelberg 1980, 206 pp.

(20) Hildegard von Bingen (1098-1179), cf. MATTHEI M., Genealogía espiritual y descendencia de Hildegardis de Bingen (1098-1179): La mujer en la perspectiva Benedictina, http: // www.uchile.cl/facultades /filosofia/ publicaciones/cyber/cyber11/matthei.html; PERNOUD R., Hildegarda de Bingen. Una conciencia inspirada del siglo XII. Barcelona, Buenos AiresMéxico 1998. FLANAGAN S., Hildegard of Bingen, 1098-1179. A visionary Life, London New York 1989, 227 pp.

(21) Guillermo de St.Thierry (1075 (1080)-1148) Cf. BLOMMESTIJN H., Guillaume de SaintThierry, DSp XII/ 2, 2389-2405.

(22) Ricardo de San Víctor (?- 1173) cf. ARIAS REYERO M., "Al principio amaba el amor". La doctrina de la Trinidad en Ricardo de San Víctor, TV 31 (1990) 163-190.

(23) Gregorio Magno (c.540-604) cf. DAGENS C., Saint Grégoire le Grand. Culture et expérience chrétiennes, Paris 1977, 475pp.

(24) Juan Escoto Eriugena (800- 877) cf. ROQUES R., Jean Scot (Erigéne), DSp VIII, 735-761.

(25) Anselmo de Canterbury (1033- 1109) Cf. HOEGEN M., L'attualitá filosofica di Anselmo d’ Aosta, Roma 1990, 143-228.

(26) Buenaventura (1217-1274) cf. LONGPRE E., Bonaventure (saint) DSp I, 1768- 1843. 


\section{1) ARTICULACIONES TEOLÓGICAS INICIALES EN GREGORIO I, ERIÚGENA Y ANSELMO}

Ubicados en el gran siglo teológico -s. XII-, resulta válido optar por el punto de vista de la teología, el intellectus fidei, ya que el período de 800-1153 resulta poco significativo. De todos modos, los períodos débiles son también muy interesantes, porque articulan una cierta imagen del mundo y de la Iglesia. En efecto, el pensamiento medieval comporta una lectura específica de aquellos que pueden llamarse sus padres fundadores: Agustín, Gregorio Magno y el Pseudo-Dionisio (27). Esta lectura presenta, sin duda, constantes: el pensamiento medieval es místico, porque orienta el hombre hacia la visión divina o la indecible unión con Dios; es político, en el sentido amplio del término, porque las sociedades son mediadas jerárquicamente (28).

El “Amor ipse notitia est”, según Gregorio I, In Euan Hom XXVII, 4.

Gregorio, hombre de "transición” y "puente”, es, por cierto, un gran teólogo si se considera al método alegórico como un procedimiento válido para el desarrollo del pensamiento teológico antropológico sistemático (29). Gregorio elabora, en la Hom XXVII, una interpretación afinada de Jn 15, 12-16, cuyo núcleo constituye la fórmula "Amor ipse notitia est" (30). A través de tres enunciados escuetos, que contextualizan

(27) Cf. KOCH J., Augustinischer und Dionysischer Neoplatonismus und das Mittelalter, ZPh 48 (1956-57) 117-133; especialmente, 119: llama la atención que Dionisio es comentado a lo largo de todo el período medieval, mientras de Agustín no se posee ningún comentario, debido a que desarrolla los problemas en sus escritos, de tal modo, que deja participar al lector en el desarrollo de sus ideas.

(28) LAFONT G., o. c., 107-208.

(29) SCHAMBECK M., Contemplatio als Missio. Zu einem Schlüsselphänomen bei Gregor dem Grossen (Studien zu systematischen und spirtuellen Theologie, 25) Würzburg 1999; - LAPORTE J., Une theologie systematique chez Gregoire? en Colloques internationaux, Gregoire Le Grand, Paris 1986, 235 -243. RAMOS-LISSON D., en torno a la exégesis de San Gregorio Magno sobre el "Cantar de los Cantares", TV 42(2001) 241-265; DOUCET M., Ontologie et economie dans la theologie de Grégoire le grand. L'episode du buisson ardent(Exode 3, 1-14), en Colloques internationaux, Gregoire Le Grand, Paris 1986, 227- 233.

(30) In Euan Hom XXVII, 4, CCHR 141, 232, 73-87. Si mens uestra appetit quod demulcet, prius bibite quod dolet. Sic sic per amarum poculum confectionis peruenitur ad gaudium salutis. Iam non dicam uos seruos, quia servus nescit quid faciat dominus eius. Vos autem dixi amicos, quia omnia quaecunque audiui a Patre meo, nota feci uobis. Quae sunt omnia quae audiuit a Patre suo, quae nota fieri uoluit seruis suis, ut eos efficeret amicos suos, nisi gaudia internae claritatis, nisi illa festa supernae patriae, quae nostris cotidie mentibus per aspirationem sui amoris imprimit? Dum enim audita supercoelestia amamus, amata iam nouimus, quia amor ipse notia esta. Omnia ergo eis nota fecerat, qui a terrenis desideriis immutati, amoris summi facibus ardebant. Istos uero amicos dei aspexerat Propheta, cum dicebat: Mihi autem nimis honorificati sunt amici tui, Deus. Amicus enim quasi animi custos uocatur. -Para el Origen y Sitz im Leben de las Homilias vale que Gregorio mismo informa sobre el origen de aquellas 40 homilías, que hizo desde noviembre 590 hasta primavera del 592 en diferentes Iglesias romanas. Debido a su débil salud Gregorio dejó escribir las primera 20 homilías y leerlas en su presencia en la iglesia, mientras el segundo libro abarca aquellas homilías hechas por él mismo, cuyo manuscrito el Papa posteriormente revisó igual como lo hizo con las 20 primeras. Se trata, por consiguiente, de unas homilías de los primeros años y medio de su pontificado. Cf. FIEDROWICZ M., Das Kirchenverständnis Gregor des Grossen: eine Untersuchung seiner exegetischen und homiletischen Werke, Freiburg 1995, 21. 
la fórmula en el n. 4, emergen los ejes fundamentales teológicos que permiten precisar el significado que adquiere el problema razón y amor en Gregorio I (31).

1. Gregorio se refiere al hecho de que "amamos las cosas celestes que hemos oído" - dum enim audita supercoelestia amamos. Se establece entonces una interrelación entre el "amar" y el "haber oido" en torno a las "cosas celestes".

Para designar el "amar", sin duda, abundan los términos, que el autor aplica en la Homilia, debido al texto joánico que interpreta, pero con matices distintos. Mientras diligere y dilectio aparecen con frecuencia, sobre todo al comienzo, en sintonía con Jn 15, 12s, amor y amare son escasos, aunque junto con la dilectio son altamente superados por la caritas. En este simple dato estadístico ya se refleja la estructura nítida de cómo Gregorio comprende el fenómeno del amor. Este amor es principalmente relación, caritas, posible solo entre dos-Hom XVII (32), pero vivido por Cristo como un -diligere-. Esto lo da a entender el contexto inmediato: mientras el "amor" se enlaza con el deseo, aquella realidad caracteríza al ser humano en su dinamismo más vital y siempre abierto a lo superior.

"Lo oído", por su parte, designa lo que viene "desde fuera" y se adentra en el corazón del hombre, expresión que Gregorio usa de preferencia, sobre todo al final de su Homilía; a su vez, se identifica con mens- y como tal contrasta con el desiderium, que tiende desde dentro hacia fuera. La dualidad intus foris, que viene preparada en la Homilia en forma explícita desde el n.2, se articula de modo transversal a través de la argumentación teológica gregoriana, alcanzando aquí su mayor densidad al evocar la fe que entra por el oído en el corazón del hombre.

¿Cuáles son, ahora, "las cosas celestes" que hemos oído y que como tales amamos? Gregorio plantea la misma pregunta en el contexto inmediato de su explicación, y contesta que se trata de lo que Jesús "ha oído de su Padre" y que ha querido dar a conocer a sus discípulos-siervos, para hacerlos "amigos suyos". Los siervos ignoran "las cosas celestes" y Jesús ha querido hacérselos saber... Resalta aquí un paso cualitativo, un cambio desde el ser "siervo" al de "amigo", lo cual Gregorio percibe a través de: "los gozos de la caridad interior" -nisi gaudia internae caritatis-, y "los regocijos de la patria celestial" nisi illa festa supernae patriae.

Indica aquí Gregorio dos factores decisivos: uno, causado por algo pasado -el paso del Espíritu Santo por el corazón, Mor 10, 8, 13-, que deja el "gozo de la caridad interna" (33) y el Espíritu Santo. El otro factor indicado está orientado por un futuro anticipado en los regocijos: la "patria celestial" (34). Ambos aspectos, que juntos esbozan magistralmente los dos extremos de la historia de salvación en su

(31) CATRY P., Désir et amour de Dieu chez saint Grégoire le Grand, RechAug 10 (1975) 269-303, especialmente, 290-296.

(32) In Euan Hom XXVII, 4, CCHR 141, 117, 7-9: Nemo enim proprie ad semetipsum habere caritatem dicitur, sed dilectione se in alterum tendit, ut esse caritas possit.

(33) PL 75, 927D-928A. Cf. CATRY P., Désir et amour de Dieu, 295, n.172. -Es preferible la variante caridad a la de claridad33, ya que permite apreciar mejor la índole relacional propia de la caridad, es decir, el nexo entre el espíritu-mente-, pese a que la edición crítica prefiere claritas.

(34) BELANGER R, Anthropologie et Parole de Dieu dans le commentaire de Gregoire Le Grand sur le Cantique des Cantiques, en Colloques internationaux de CNRS, Gregoire Le Grand, Paris 1986, 245-254. 
dimensión individual y colectiva, según el pensamiento gregoriano, explican por qué nostris quotidie mentibus per aspirationem sui amoris imprimit se; es decir, fijan las "aspiraciones amoris sui" en nuestros corazones-mente. Nuestra estructura mental, marcada por el desiderium, ha recibido una calidad nueva, se torna aspiratio.

El enunciado "amamos las cosas que hemos oído" sintetiza las aspirationes amoris sui. Prevalece, sin duda, la acentuación del amor, mientras el conocer-saber como actividad de la razón, solo es mencionado, de modo subordinado. Esta acentuación, sin embargo, luego, parece invertirse.

2. "Lo amado, ya lo conocemos" -amata iam novimus. Sin duda, este amata, el haber sido amado, se refiere al acto "sido hecho amigo de Jesús, tal como Él quiso hacerles notar". La iniciativa de Jesús precede al conocimiento de los discípulos. Gregorio retorna al querer, a la voluntad de Jesús de "dar a conocer", y subraya que lo dicho se confirma por el cambio de ser "siervo" a "amigo". Se trata, entonces, de un conocimiento que brota como consecuencia de la amistad, lo cual permite deducir que el amor ipse notitia est. Pero, de nuevo, no es el conocimiento el que interesa, sino el amor (35).

3. Finalmente, Gregorio pone de relieve el cambio concreto de una existencia marcada por los "deseos terrenos" -desideriis- en el pasado de aquellos que ardían en las llamas del sumo amor-Quia ergo eis nota fecerat, qui, a terrenis desideriis immutati, amoris summi facibus ardebant. El haber dado a conocer todo esto requiere de la presencia del amor divino, expresado aquí y por el símbolo del fuego, que Gregorio evoca (36).

Sintetizando, Gregorio I soluciona el problema razón y amor desde el amor, con matices destacadamente bíblicos-relacionales, donde el aspecto racional y gnoseológico pasa a segundo plano. Esto se aprecia con mayor claridad en una comparación con el significado teológico del enunciado de Gregorio de Nisa, An et res 97: el conocimiento llega a ser amor, después del ascenso persistente del alma racional hacia el sumo bien, aunque anticipado por el "carisma de la gnosis" (37).

\section{b) El "superessentialiter "a la razón y el amor en Eriúgena, Periph I.}

Juan Escoto Eriugena, figura como uno de los más sorprendentes autores del pensamiento especulativo en la Temprana Edad Media, entre Agustín y Anselmo (38). Su gran mérito radica en haber destacado el valor de la ratio recta. Acorde a la S. E., Juan Escoto ofrece en Periph I (39) una rationatio rigurosa respecto de la

(35) Cf. DISSE J., o. c., 222, n.41. quien afirma lo contrario, al constatar, que "Balthasar kehrt gewissermassen den Satz Gregors des Grossen: Amor ipse notia est, um".

(36) Cf. GAILLARD J., Feu, DS V, 245- 273.

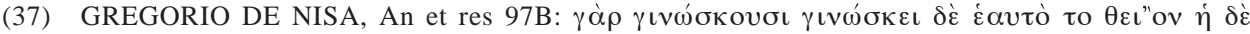

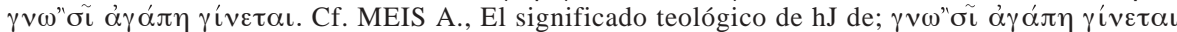
(De an et res, $\mathrm{PG} 46,96.37$ ) de Gregorio de Nisa y su recepción por Guillermo de Saint Thierry TV 43 (2002) 285-302.

(38) BEIERWALTES W., Eriugena. Studien zu seinen Quellen. Vorträge des III. Internationalen Eriugena-Colloquiums. Freiburg im Breisgau. 27-30. August 1979 (Abhandlungen der Heidelberger Akademie der Wissenschaften) Heidelberg 1980, 206 pp.

(39) IOHANNEIS SCOTTI SEU ERIVGENAE, PERIPHYSEON I (CCHR111) TURNOLT 1996, 3270-3496 cf. ROQUES R., Jean Scot (Erigéne), DSp VIII, 735-761. 
aplicación del amor a Dios, una vez que se le haya negado toda categoría en el sentido aristotélico a la luz de la cuádruple división del ser (40). Con esto, el problema razón y amor ofrece una apertura hacia dimensiones nuevas, avaladas por Dionisio Areopagita (41).

\section{Dios, esencia inefable}

Cuando al final de la extensa argumentación del Periph I Eriúgena concluye que ninguna categoría es aplicable a Dios (42), el Magíster fundamenta tal conclusión a través del triple paso propio del método eriugeneano: recurre a la S.E., para afimar que, según ella se puede predicar de Dios que Él quiere, ama, ve, escucha, lo cual, de inmediato, es negado por ser Dios "más" - plus- que esencia. De ello se concluye que Dios es una esencia inefable (43). Lo mismo se argumenta respecto de la simplicitas de Dios (44): se escucha que Él ama y es amado, sin que se pueda distinguir alguna diferencia entre amante y amado, como tampoco entre desear y ser deseado. Es decir, Dios es simple (45).

\section{Dios-Amor}

Para abordar la verdad bíblica del Dios-Amor, el autor procede con sumo cuidado: parte de una doble definición del amor en cuanto" nexo y vínculo de todas las cosas en una amistad inefable e indisoluble" (46), y "fin y reposo natural del

(40) Cf. SCHRIMPF G., Das Werk des Johannes Scottus Eriugena im Rahmen des Wissenschaftsverständnisses seiner Zeit Eine Einführung zu Periphyseon (Beiträge zur Geschichte der Philosophie und Theologie des Mittelalters, Neue Folge, 23) Münster 1982, 132ss; IDEM., Johannes Scottus Eriugena und die Rezeption des Martianus Capella im karolingischen Bildungswesen, en BEIERWALTES W., (Hrg), Eriugena . Studien zu seinen Quellen. Vorträge des III. Internationalen Eriugena-Colloquiums, Freiburg im Breisgau 27.-30. August 1979, 135-148. Cf. FORTUNY F. J., Juan Escoto Eriúgena: subjetividad divina y teología negativa, TV 43 (2002). 228-250

(41) Cf. BEIERWALTES W., Eriugena. Studien zu seinen Quellen, 206 pp; KOCH J., Augustinischer und Dionysischer Neuplatonismus und das Mittelalter, PhJ 48 (1956-57) 117-133.

(42) DN I, CCHR111, 105, 3270: A. Hoc quoque clare perspicio. Et iam nunc nullam kategoriam in deum cadere incunctanter intelligo.

(43) DN I, CCHR111, 105, 3272-78: N.Quid igitur? Num eadem ratione debemus inspicere omnium uerborum quae sancta scriptura de diuina natura praedicat uirtutem, ut nil aliud per ea aestimemus significari praeter ipsam simplicem incommutabilem incomprehensibilemque omni intelectu ac lectu ac significatione diuinam essentiam et plus quam essentiam?

(44) DN I, CCHR111, 105, 3276-3284: Verbi gratia, dum audimus deum uelle et amare aut diligere, uidere, audire caeteraque uerba quae de eo praedicari possunt, nil aliud oportet nos cogitare nisi ineffabilem ipsius essentiam atque uirtutem connaturalibus nobis significationibus suaderi, ne in tantum uera ac pia christiana religio de creatore omnium sileat ut nil de eo fari audeat ad simplicium animorum instructionem haereticorumque semper ueritati insidiantium eamque eruere laborantium minusque in ea eruditos fallere appetentiuum refellendas astutias.

(45) DN I, CCHR111, 105, 3284-3288: Non aliud itaque deo esse et uelle et facere et amare et diligere et uidere caeteraque huiusmodi quae de eo, ut diximus, possunt praedicari, sed haec omnia in ipso unum id ipsumque accipiendum suamque ineffabilem essentiam eo modo quo se significari sinit insinuant.

(46) DN I, CCHR111, 106, 3303-3308: Nec in talibus deceptum te reor; ita enim sunt ut arbitraris. Primum igitur hanc amoris diffinitionem accipe: Amor est connexio ac uinculum, quo omnium rerum uniuersitas ineffabili amicitia insolubilique unitate copulatur... DN I, CCHR111, 105, 3289-106, 3297: Non aliud quidem. Vbi enim est uera et aeterna et insolubilis per se ipsam 
movimiento de todas las cosas" (47). Avala lo dicho por Dioniso de Areopagita y afirma lo que predica la S.E. del Dios Amor, para proceder luego a negar con la razón lo afirmado, de tal modo, que cabe trascender lo afirmado y lo negado hacia el plus de Dios como tal (48).

Dios, en efecto, es llamado Amor en la S. E, porque -explica- la razón es "causa de amor", tanto a través del movimiento de egreso como de regreso (49). Pues a la luz de la mirada de la mente racional, Dios difunde el amor a través de las cosas: "ama" (50). Pero es también "amado", porque todas las cosas tienden a Él y su belleza las atrae, a modo de un imán, en cuanto suma bondad (51). Eriúgena basa esta afirmación nuevamente en Dionisio, quien enlaza connaturalmente el amor con el deseo en su concepto del Dios-Amor (52). Con unos ejemplos sensibles, adaptados de la luz y del fuego, el autor complementa la argumentación racional "científica" desde las artes liberales" (53).

simplicitas, ibi aliud et aliud et multum diuersumque fieri impossibile est. Vellem tamen apertius mihi suadeas ut clare uideam, dum audio deum amare uel amari, nil aliud nisi ipsius naturam sine ullo motu amantis uel amati intelligam. Cum enim hoc mihi fuerit suasum, nequaquam haesitabo ubicunque legero seu audiero ipsum uelle uel desiderare et desiderari, deligere et deligi, uidere et uideri, appetere et appeti, mouere similiter et moueri.

(47) DN I, CCHR111, 106, 3306-3308. Potest et sic diffiniri: Amor est naturalis motus omnium rerum quae in motu sunt finis quietaque statio, ultra quam nullus creaturae progreditur motus.

(48) DN I, CCHR111, 106, 3308-3314: His diffinitionibus aperte sanctus Dionysius astipulatur in amatoriis omnis sic dicens: "Amorem, siue diuinum siue angelicum siue intellectualem siue animalem siue naturalem dicamus, unitiuam quandam et continuatiuam intelligamus uirtutem superiora quidem mouentem in prouidentiam inferiorum, et aequiformia iterum in sociabilem uicissitudinem, et nouissima subiecta ad meliorum et superpositorum conuersionem".

(49) DN I, CCHR111, 107, 3329-3332: Merito ergo amor deus dicitur, quia omnis amoris causa est et per omnia diffunditur, et in unum colligit omnia et ad se ipsum ineffabili regressu reuoluitur, totiusque creaturae amatorios motus in se ipso terminat.

(50) DN I, CCHR111, 107, 3332-3341: Ipsa quoque diuinae naturae in omnia quae in ea et ab ea sunt diffusio omnia amare dicitur, non quia ullo modo diffundatur quod omni motu caret omniaque simul implet, sed quia rationabílis mentis contuitum per omnia diffundit et mouet, dum diffusionis et motus animi causa sit ad eum inquirendum et inueniendum et quantum possibile est intelligendum, qui omnia implet ut sint et uniuersalis ueluti amoris pacifica copulatione in unitatem inseparabilem, quae est quod ipse est, uniuersa colligit et inseparabiliter comprehendit.

(51) DN I, CCHR111, 107, 3341-3354 Amari item dicitur ab omnibus quae ab eo sunt, non quod ab eis aliquid patiatur qui solus impassibilis est, sed quia eum omnia appetunt ipsiusque pulchritudo omnia ad se attrahit. Ipse enim solus uere amabilis est, quia solus summa ac uera bonitas et pulchritudo est. Omne siquidem quodcunque in creaturis uere bonum uereque pulchrum amabileque intelligitur ipse est. Sicut enim nullum bonum essentiale est, ita nullum pulchrum seu amabile essentiale praeter ipsum solum. Sicut ergo lapis ille, qui dicitur magnetes, quamuis naturali sua uirtute ferrum sibimet propinquans ad se attrahat, nullo modo tamen ut hoc faciat se ipsum mouet aut a ferro aliquid patitur quod ad se attrahit, ita rerum omnium causa omnia quae ex se sunt ad se ipsam reducit sine ullo sui motu sed sola suae pulchritudinis uirtute.

(52) DN I, CCHR111, 107, 3353-3356: Hinc idem "sanctus Dionisius inter caetera ait: 'Quare autem theologi deum aliquando quidem amorem, aliquando uero delectionem, aliquando amabile et delectabile euocant?'

(53) DN I, CCHR111, 108, 3386-3395: Quid dicam de artibus, quas sapientes liberales appellant disciplinas, quae dum in semet ipsis per semet ipsas plenae integrae immutabilesque permanent, moueri tamen dicuntur quando rationabilis animi contuitum ad se quaerendas, inueniendas permouent, et ad se considerandas attrahunt ita ut et ipsae dum per se, ut diximus, immutabiles sunt, moueri tamen in mentibus sapientum uideantur cum eas moueant. Et multa alia in quibus diuinae uirtutis obscura conspicitur similitudo. 
Después de haberse extendido bastante en la parte afirmativa, con especial atención a la dualidad activo-pasivo, tal como la caracteriza el fenómeno del amor, Eriúgena niega bruscamente todo lo afirmado, e insiste en que Dios está encima de toda semejanza en cuanto no es amor (54).

El autor da, de inmediato, el último paso, afirmando que Dios es más que amor y ser amado, porque es una natura supraessentialis (55). Con lo cual resalta fundamentalmente la índole supra, divina propiamente tal, que ya no puede pensarse, sino que solo debe alabarse sobremanera-superlaudanda (56). Este paso más allá de la razón humana, sin duda desesencializa a Dios por medio de la razón. Pero, de esta manera, ¿no se desdibujan los contornos, el rostro de Dios, tan relevante si de amor se trata? (57) De todos modos, es el theo-logos que se aproxima a la razón, que no entra en ella como en Gregorio I, sino se une a ella "desde fuera" (58).

\section{Dios-Trinidad}

El paso decisivo hacia el Dios Trinidad no lo puede iniciar la razón humana, solo es posible gracias al "Verbo Encarnado", aunque no sin la razón. Tan solo que la compenetración del "intellectus del Señor" con la ratio vera se estrecha hasta tal punto, que la última peligra quedar absorbida por la primera en el triple movimiento de afirmación, negación y trascendencia (59).

En un primer momento, Eriúgena admite el hecho de que la ratio vera coge semejanzas, lo cual explicita mejor en el texto paralelo de la Vox spiritualis como "participación en la luz", en cuanto capacidad de nuestra naturaleza; aunque la luz viene desde fuera, conoce no por propia fuerza, sino por la luz divina, que le es infundida en cuanto gracia (60). Por tanto, el autor insiste: es el "Verbo Encarnado" y no nosotros, es el Espirítu de vuestro Padre el que habla en vosotros (61).

Tal afirmación, que emerge de la negación -las etapas se invierten-, conlleva esta insistencia: es el Espíritu, quien ama y ve al Hijo y al Padre en nosotros. Se

(54) DN I, CCHR111, 109, 3402-4305; Deus itaque per se ipsum amor est, per se ipsum uisio, per se ipsum motus, et tamen neque motus est neque uisio neque amor sed plus quam amor, plus quam uisio, plus quam motus.

(55) DN I, CCHR111, 109, 3424-3425: Verius enim negatur deus quid eorum quae de eo praedicantur esse quam affirmatur esse.

(56) DN I, CCHR111, 109, 3426-3428: Deinde super omne quod de eo praedicatur superessentialis natura, quae omnia creat et non creatur, superessentialiter superlaudanda est.

(57) DN I, CCHR111, 110, 3435-3440: Si ergo se ipsam sancta trinitas in nobis et in se ipsa amat se ipsam et uidet et mouet, pro certo a se ipsa amatur, uidetur, mouetur secundum excellentissimum modum nulli creaturae cognitum, quo se ipsam et amat et uidet et mouet, et a se ipsa in se ipsa et in creaturis suis amatur, uidetur, mouetur, cum sit super omnia quae de se dicuntur.

(58) DN I, CCHR111, 110, 3440-3441: De ineffabili enim quis et quid potest fari?

(59) Este triple paso lo acompaña el autor por la símbología frecuente del fuego. Cf. JEAUNEAU E., Jean Scot et la métaphysiu que feu, en Etudes érigíniennes, Paris 1987, 750 pp.

(60) Jean Scot, Homélie sur le prologue de Jean, ed.E. Jeauneau (SC 151) Paris 1969, 266.

(61) DN I, CCHR111, 109, 3428- 110, 3434: Quod ergo deus uerbum caro factum suis discipulis ait "Non uos estis qui loquimini, sed spiritus patris qui o loquitur in uobis" - uera ratio cogit nos de aliis similibus similiter credere, dicere, intelligere: Non uos estis qui amatis, qui uidetis, qui mouetis, sed spiritus patris, qui loquitur in uobis ueritatem de me et patre meo et se ipso, ipse amat et uidet me et patrem meum et se ipsum in uobis, 
mueve en nosotros para que amemos al Hijo y al Padre: egreso y regreso son producidos por Dios mismo en el ser humano (62).

Esto lleva al tercer paso, la conclusión por excelencia: Si la Sma. Trinidad se ama a sí misma, entonces es amada por sí misma, según un modo excelente, inefable, en cuanto "nombre, Verbo, vox: quien conoce el intelecto del Señor" (63).

\section{Dios, más allá del ser}

Al poner fin a su rationatio, Eriúgena sintetiza magistralmente todo contenido expuesto por medio de Dionisio, quien atestigua que Dios es tanto quietud como movimiento, en su triple dirección, recto, espiritual y circular, es decir, Dios está más allá del ser.

Resumiendo puede apreciarse que la solución eriugeneana al problema razón y amor da prioridad a la razón, con ayuda de su fuente principal, Dionisio Areopagita. Contrariamente a Gregorio Magno, el impresionante rigor científico de la rationatio conlleva una despersonalización del rostro de lo concreto, afectando seriamente la subsistencia libre del ser humano en cuanto criatura, lo cual se aprecia, sobre todo, en la descripción del Dios Trino, que se sirve del ser humano como de una "caja de resonancia”.

\section{c) El "sola ratione", anticipado por el amor segun Anselmo M 66-68.}

Para Anselmo, lo que hay que pensar es el pensar mismo (64). Así, pues, la pregunta de si es filósofo o es teólogo (65) conduce no solo al núcleo de la teología anselmiana, sino que articula el problema razón y amor con una densidad nueva, más allá del modelo agustiniano y su confluencia con las fuentes griegas (66). Esta densidad alcanza su punto culminante en la argumentación $M$ 66-68 (67), cuando Anselmo, después de un largo ascenso, ha constatado en M 64, que es necesario desistir de la comprensión sola ratione del Misterio-res secreta-, que está encima de todo y del cual solo se sabe con certeza que existe, pero no cómo es-sicuti est (68).

(62) DN I, CCHR111, 109, 110, 3434-3435: et mouet se ipsum in uobis ut diligatis me et patrem meum.

(63) SC, 151, 266, 24-26: non uos estis qui intelligitis me, sed ego ipse in uobis per spiritum meum meipsum intelligo, quia uos non estis substantialis lux, sed participatio per se subsistentis luminis. Cf. Mt 10, 20

(64) KIENZLER K., Glauben und Denken bei Anselm von Canterbury, Freiburg-Basel-Wien 1981, 71 158; HUBERT A., Teología monástica y teología escolástica: el aporte de San Anselmo de Canterbury, Anales Concepción (2000) 45-60.

(65) Cf. M. HOEGEN, Einführung, en L' attualitá filosofica di Anselmo d’ Aosta, Roma 1990, 5-10; 143-228.

(66) Cf. M. CORBIN, Priere et raison de la foi. Intruduction a l'oeuvre de Saint Anselme de Cantorbery, Paris 1992, 430-445

(67) Cf. L' oeuvre de S.Anselme de Cantorbery I, (ed.M.Corbin), Paris1986, 77-79; Cf.SALMANN E., Korreflexive Vernunft und Theonome Weisheit in der Logik von Monologion und Proslogion, en M. HOEGEN, L' attualitá filosofica di Anselmo d' Aosta, Roma 1990, 176-180.

(68) M 64: Videtur mihi huius tam sublimis rei secretum transcendere omnem intellectus aciem humani... quamvis sic intellectu penetrari non possint, ut et verbis valeant explicari, nullatenus tamen certudinis eorum nutat soliditas. Nam si superior consideratio rationabiliter comprehendit incomprensibile esse, quomodo eadem summa sapientia sciat ea quae fecit, de quibus tam multa nos scire necesse est. 
Ello permite desplazarse desde el conocimiento cierto al de in ainigmata (69), que conoce no en sí, sino a través de algo distinto de sí, per aliud. (70)

1. El “...per aliud” del “magis” de la razón (M66)

Anselmo parte de un hecho evidente: la suprema naturaleza no puede ser comprendida en sí, sino a través de algo distinto de ella. Luego, expone aquella idea que le sirve de hilo conductor para toda su argumentación: es seguro-certum- que lo que más -magis- accede al conocimiento del Misterio es aquello que le es más-magiscercano por la semejanza (71). Pero ¿qué es lo que se le aproxima más, si no la mente racional misma? Ella, en efecto, ayuda más a aproximarse a la suma verdad por su esencia superior a todo lo creado (72), y le permite también aprender mejor lo que debe pensar de la esencia creada a partir de sí misma (73). Este doble principio del pensar, referido a Dios y per aliud, se explicita con mayor nitidez como verdadera imagen de la Trinidad (74).

\section{La "vera imago" de la Trinidad en la mente racional (M67)}

A través de un giro brusco, que Anselmo no fundamenta mayormente, aunque lo prepara (75), el autor constata -67- que la mente racional es "como un espejo creado para sí misma" (76), espejo en el cual puede ver la imagen de aquella esencia que ella no puede ver cara a cara (77). Pues, argumenta Anselmo, "si esta mente es la única entre todas las cosas creadas que puede acordarse de sí misma-memorcomprenderse-intelligere- y amarse-amare, no se le puede negar que hay en ella la imagen verdadera de aquella esencia en la cual la memoria, la inteligencia y el amor

(69) M 65: Sic igitur illa natura et ineffabilis est, quia per verba sicuti est nullatenus valet intimari; et falsum non est, si quid de illa ratione docente per aliud velut in aenigmate potest aestimari.

(70) M 66: Cum igitur pateat quia nihil de hac natura possit percipi per suam proprietatem sed per aliud.

(71) M 66: certum est quia per illud magis ad eius cognitionem acceditur, quod illi magis per similitudinem propinquat

(72) M 66: quidquid enim inter creata constat illi esse similius, id necesse est esse natura prastantius. Quapropter id et per maiorem similitudinem plus iuvat mentem indagantem summae veritati propinquare, et per excellentiorem creatam essentiam plus docet, quid de creante mens ipsa debeat aestimare.

(73) M 66: Patet itaque quia, sicut sola est mens rationalis inter omnes creaturas, quae ad eius investigationem assurgere valeat, ita nihilominus cadem sola est, per guam maxime ipsamet ad ciusdem inventionem proficere queat. Nam iam cognitum est, quia hace illi maxime per naturalis essentiae propinquat similitudinem.

(74) M 66: Quid igitur apertius quam quia mens rationalis quanto studiosius ad se discendum intendit, tanto efficacius ad illius cognitionem ascendit; et quanto scipsam intueri negligit, tanto ab eius speculatione descendit?

(75) SALMANN E., o. c., 180: No se debe olvidar que la vuelta del pensar sobre sí mismo en M 67 no se fundamenta, como tampoco se lo hace con la afirmación del primado de Dios en M 33. Queda en evidencia solo que el pensar, se trasciende cada vez más en la medida en que se escucha a sí mismo y reflexiona y se realiza mejor su ser propio, recibido como tarea, en la medida en que el pensar sale de sí a través del éxtasis. Esta idea está en el trasfondo de M 67s, pero a modo de afirmación más que de una argumentación seria conclusiva

(76) M 67: Aptissime igitur ipsa sibimet esse velut "speculum" dici potest.

(77) M 67: in quo speculetur it ita dicam imaginem eius, quam "facie ad faciem" videre nequit. 
constituyen una trinidad inefable" (78). De ahí que para Anselmo esa Trinidad hace ver a la mente "cuán semejante le es por la facultad que tiene de recordarse de ella, de comprenderla y amarla" (79).

Una vez puesto de relieve tal semejanza de la mente con la Trinidad, Anselmo concluye: "No se puede pensar razonablemente que haya podido darse a una criatura inteligente nada más importante, más parecido a la sabiduría suprema (80), que esta facultad por la cual puede recordar, comprender y amar lo que es excelente y grande por encima de todo (81). Al resaltar así el magis queda totalmente evidente que "no hay otra criatura que sea hasta tal punto imagen del Creador" (82).

\section{El amor, realización debida, siempre mayor del ser criatura racional}

Parece lógico para Anselmo -M 68- que, más allá de poner de relieve la estructura óntica de la criatura racional, resaltando su dignidad, cabe insistir en el deber-debet- de realizar -exprimere- la imagen, impresa naturalmente en su mente como capacidad, por un actuar -effectum - según la voluntad (83). Esto no solo es cuestión de gratitud (84): es un deber por excelencia, al cual no puede anteponerse nada, es decir, recordar el Bien supremo, conocerlo y amarlo (85).

Las razones son las siguientes: no cabe duda que lo que ya es imagen en potentia, tiene que ser más -magis- en la voluntad ${ }^{86}$. Además, el ser racional de la naturaleza racional no es pues otra cuestión que distinguir lo justo de lo no justo, lo verdadero de lo no verdadero, lo bueno de lo no bueno, lo mejor de lo menos bueno (87). Esto, sin embargo, sería totalmente inútil y superfluo, si la mente no ama o rechaza aquello que distingue (88). De ahí que resulte obvio que toda la racionalidad existe para amar o rechazar más o menos aquello que es juzgado por la razón como más o menos bueno o no bueno (89).

(78) M 67 Nam si mens ipsa sola ex omnibus quae facta sunt, sui memor et intelligens et amans esse potest: non video cur negetur esse in illa vera imago illius essentiae, quae per sui memoriam et intelligentiam et amorem in trinitate ineffabili consistit.

(79) M 67 Aut certe inde verius esse illius se probat imaginem, quia illius potest esse memor, illam intelligere et amare. In quo enim maior est et illi similior, in eo verior illius esse imago cognoscitur.

(80) M 67 Omnino autem cogitari non potest rationali creaturae naturatiter esse datum aliquid tam praecipuum tamque simile summae sapientiae,

(81) M 67 quam hoc quia potest reminisci et intelligere et amare id, quod optimum et maximum est omnium.

(82) M 67 Nihil igitur aliud est inditum alicui creaturae, quod sic praeferat imaginem creatoris.

(83) M 68 Consequi itaque videtur quia rationalis creatura nihil tantum debet studere, quam hane imaginem sibi per naturalem potentiam impressam per voluntarium effectum exprimere.

(84) M 68: Etenim praeter hoc quia creanti se debet hoc ipsum quod est:

(85) M 68: hinc quoque quia nil tam praecipuum posse quam reminisci et intelligere et amare summum bonum cognoscitur, nimirum nihil tam praecipue debere velle convincitur.

(86) M 68: Quis enim neget quaecumque meliora sunt in potestate, ea magis esse debere in voluntate?

(87) M 68: Denique rationali naturae non est aliud esse rationalem, quam posse, discernere iustum a non iusto, verum a non vero, bonum a non bono, magis bonum a minus bono

(88) M 68 Hoc autem posse omnino inutile illi est et supervacuum, nisi quod discernit amet aut reprobet secundum verae discretionis iudicium.

(89) M 68: Hine itaque satis patenter videtur omne rationale ad hoc existere, ut sicut ratione discretionis aliquid magis vel minus bonum sive non bonum iudicat, ita magis vel minus id amet aut respuat. 
Anselmo pasa de la evidencia de la semejanza, a la mayor evidencia: la criatura racional fue creada para amar la suprema esencia, encima de todos los bienes, que es el Bien supremo (90). Esto, sin embargo, no puede practicarse sin amarlo, sin acordarse de ella-reminiscit- y sin esforzarse-studere-por comprenderla-intelligere (91). En conclusión: "La criatura racional debe poner todo su empeño y voluntad en recordar, comprender y amar el bien supremo, único objeto para el cual sabe que ha recibido la existencia" (92).

En síntesis, el problema razón y amor recibe una solución en Anselmo, quien, siguiendo a Agustín, afirma, con más rigor, el mismo pensar a través de las diversas dualidades: in ainigmata y el cara a cara; ascenso más allá de/ entrada en sí mismo; el per aliud lad imagen. De tal modo, contrario a Eriúgena, se hace evidente la compenetración encontrada en Gregorio Magno, en cuanto inesse del amare por el intelligere, que se funda en una tercera dimensión, sin embargo, el reminiscere. De todos modos, prima el amor acorde a la bondad. Pues, más que explicar la ratio, el autor pone de relieve la preeminencia del amor (93). El rostro propio del Creador y de la criatura se explicita mejor en el Proslogion que en Monologion 64-68 (94).

\section{2) LA “INTELECCIÓN ARDIENTE”, SEGÚN HILDEGARD VON BINGEN SCIVIAS II 1-9}

Hildegard von Bingen, "competente teóloga de la Temprana Escolática" (95), representa una mujer notable, cuyo discurso teológico no solo se gesta desde conceptos dogmáticos sólidos, sino que integra las "visiones" y símbolos complejos (96), sobre todo, "ígneos", en su argumentación histórico salvífica, de índole profética trinitaria (97). Se trata de una manera curiosa de argumentar (98), que representa un desafío peculiar para la Teología en cuanto lucha contra los cátaros y Abelardo (99).

(90) M 68: Nihil igitur apertius quam rationalem creaturem ad hoc esse factam, ut summam essentiam amet super omnia bona, sicut ipsa est summum bonum; immo ut nihil amet nisi illam aut propter illam, quia illa est bona per se, et nihil aliud est bonum nisi per illam.

(91) M 68: Amare autem eam nequit, nisi eius reminisci et eam studuerit intelligere.

(92) M 68: Clarum ergo est rationalem creaturam totum suum posse et velle ad memorandum et intelligendum et amandum summum bonum impendere debere, ad quod ipsum esse suum se cognoscit habere.

(93) Según J. DISSE, o.c., 218 Balthasar iría contra la concepción trinitaria de Anselmo, lo cual significa un juicio poco acorde a los textos analizados.

(94) ULRICH F., Cur non video praesentem? Zur Implikation der "griechischen" und "lateinischen" Denkform bei Anselm und Scotus Erigena, FZPT 22 (1975)70-170.

(95) Según B. J. HILBERATH, Das Athanasianische Glaubensbekenntnis in der Auslegung Hildegards von Bingen. Bemerkungen zur Trinitätslehre, $\mathrm{ThPh}$ 63(1988) 321-341, especialmente 321, esto es un dato asombroso.

(96) KÜHNE U., Die Konstruktion prophetischen Sprechens. Hildegards Sicht der eigenen Rolle als Autorin, FZTP 113(1999) 67-78.

(97) GÖSEBRINK H. M., "Ich sah einer sehr grossen Glanz”. Vision des Selbstverständnis und Vision der Theologie bei Hildegard von Bingen, Erbe und Auftrag 74 (1998)9-27. WIDMER B., Heilsordnung und Zeitgeschehen in der Mystik Hildegards von Bingen (Basler Beiträge zur Geschichtswissenschaft, 52) Basel Stuttgart 1955, 286 pp.

(98) Merkwürdig comenta Goethe, después de haber leido algún escrito de la autora

(99) Cf. FLANAGAN S., Hildegard of Bingen, 1098-1179. A visionary Life, London New York 1989, 227pp; MEIER C., Eriugena im Nonnenkloster? Überlegungen zum Verhältnis von 
Como tal se distingue de los autores anteriores, en lo que se refiere a la comprensión del problema razón y amor, que se abordará a partir de Scivias II, 1-9 (100).

a)

\section{El "intellectualis sensus" del Misterio}

La visión 2, de la II parte de $S c$, se inicia con la insistencia en el sensus, aludiendo a los "sentidos", con que también concluye dicha visión en II, 9. Ello esboza una estructura antropológica básica abierta al mundo, pero orientada hacia los "misterios de Dios" (101). Cuando la versión castellana traduce el sensus como "sentir" y la alemana habla de "significado", emerge una "racionalidad" que se constituye tanto por una receptividad compleja como por una espontaneidad lúcida (102).

La expresión discrete cernatur y el intelligere que circunscriben el sensus, corresponden, en efecto, a los sentidos básicos del olfato y del gusto. Pero se vuelcan sobre la plenitud de la creación existente en cuanto discernimiento. La autora, sin duda, aquí apunta contra los cátaros.

De este modo, a través del in pleno opere cernatur se descubre una plenitud nunca vista en la viriditas, cuya belleza y bondad trasciende su origen fundante, el fabricator. Que este Creador existe, no puede ponerse en duda; tampoco se puede negar que esté repleto por dentro, y no vacío. Pero quién es El, no lo discernirá nunca ni el sensus ni el intellectus, sino la "visión", que da cuenta de El en vivos colores y movimientos.

La "visión" de Dios Trino y Uno

La visión, que implica tanto colores, símbolos y formas, describe de modo imponente quién es Dios en cuanto Padre, Hijo y Espíritu Santo en la unidad de su ser (103). La índole propia de cada persona se describe tanto "en sî", como en el "para quién", y como tal ser uno. A través de los colores como también de sus efectos concretos emerge el contenido dogmático incuestionable en cuanto verdad teológica.

Prophetentum und Werkgestalt in den figmenta prophetica Hildegards von Bingen, Frühchristlichen Studien 19 (1985) 466-496.

(100) El más reciente análisis de Scivis, primera parte de la gran trilogía, que aborda también el Liber Vitae Meritorum y el Liber Divinorum Operum es de ZÖLLER M., Gott weist dem Volke seine Wege. Die theologische Konzeption des <Liber Scivias> der Hildegrad von Bingen (1098-1179) (TSTP, 11) Tübingen, Basel 1997, 610 s. Cf. HILDEGARDA DE BINGEN, Scivias: Conoce los caminos, Madrid 1999.

(101) Sc II, CCHR 43, 124, 23-30: Hic est sensus misteriorum Dei ut discrete cernatur et intellegatur quae sit plenitudo illa quae numquam uisa est in ortu et in qua nullus defectus est illi acutae fortitudini quae plantauit omnes riuulos fortium. Nam si Dominus uacuus esset propriae uiriditatis suae, quid tunc esset opus illius? Videlicet uanum. Ideoque in pleno opere cernitur quis fabricator sit.

(102) CHAVEZ ALVAREZ F., "Die brennende Vernunft". Studien zur Semantik der rationalitas" bei Hildegard von Bingen ( Mystik in Geschichte und Gegenwart). Texte und Untersuchungen, Abt.I: Christliche Mystik, 8), Stuttgart-Bad Cannstatt 1991, 282 pp.

(103) Sc II, CCHR 43, 124, 13-21: DEINDE VIDI serenissimam lucem et in ipsa sapphirini coloris speciem hominis, quae tota suauissimo rutilante igne flagrabat. Et illa serena lux perfudit totum illum rutilantem ignem, et ille rutilans ignis totam illam serenam lucem, ac eadem serena lux et idem rutilans ignis totam speciem eiusdem hominis, ita lumen unum in una ui possibilitatis exsistentes. Et iterum audiui candem uiuentem lucem mihi dicentem. 
Si el Padre -esta luz serenísima-, lo es por tener un Hijo-per filium- (104), el Hijo a través de la figura humana irradia la luz de la verdad por el mundo y constituye a través de esta plenitud un origen de las criaturas-ortum creaturarum- (105). El Espíritu Santo, por su parte, como fuego rutilante suavísimo, acentúa la índole ígnea de Dios, en cuanto inseparable de la majestad divina, pero a su vez, encendiendo los corazones de los fieles (106).

Esta imponente descripción de los Tres, totum in uno (107), apela a la dimensión más profunda del sentir humano con la insistencia en ut ardeat in amore meo; es decir, el intellectus sensualis se completa por el amor, invirtiendo la perspectiva del eros: el aceso a Dios viene de Dios, de su amor (108).

\section{c) El "ardor" del amor de Dios"}

Cuando luego se aborda el amor meus, que viene de Dios, según la cita 1 Jn 4, 16 y que se explicita detenidamente como una anticipación de Dios al hombre (109), se pretende no solo producir el efecto señalado, arder en el amor de Dios, sino que también se describe este amor de tal modo que se lo comprenda como un amor de los Tres en uno, exhortando al intelligere.

La intelección de la anticipación de tal amor de Dios se revela como condición fundante en una simultaneidad de rasgos propios y donación ad extra. El Padre se revela como origen fontanal por su caridad. A su vez, por su Verbo esta se infunde en el mundo. Pero es la caridad profundísima, suavísima, la materna dilectio amplexione, en cuanto Espíritu Santo, como lo dice su nombre.

En efecto, este amor se vuelca tal cual sobre el hombre, como lo concreta su creación de barro y el spiraculum recibido. De tal forma, puede apreciarse una participación connatural, aunque regalada, del hombre en el ardor de Dios por medio del amor.

El diligere debe "ser entendido" no en vano aparece la misma exhortación tres veces: homo intelligere. De tal modo, el ardere se realiza en el Espíritu Santo, -superlativo- como un intelligere, que a continuación se explica de modo trinitario.

(104) Sc II, CCHR 43, 125, 31-37: Quapropter uides serenissimam lucem, quae sine macula illusionis, defectionis ac fallaciae designat Patrem, et in ipsa sapphirini coloris speciem hominis, quae sine macula obduirationis, inuidiae et iniquitatis declarat Filium, ante tempora secundum diuinitatem a Patre genitum,

(105) Sc II, CCHR 43, 125, 34-37: declarat Filium, ante tempora secundum diuinitatem a Patre genitum, sed post in tempore secundum humanitatem in mundo incarnatum;

(106) Sc II, CCHR 43, 125, 37-41: quae tota suauissimo rutilante igne flagrat, qui ignis sine niacula ariditatis, mortalitatis atque tenebrositatis demonstrat Spiritum sanctum, de quo idem Vnigenitus Dei secundum carnem conceptus et de Virgine temporaliter natus, lumen uerae claritatis mundo infudit.

(107) Sc II, CCHR 43, 125, 41-46: Sed quod illa serena lux perfundit totum illum rutilantem ignem, et ille rutilans ignis totam illam serenam lucem, ac eadem serena lux et idem rutilans ignis totam speciem eiusdem hominis, ita lumen unum in una ui possibilitatis exsistentes:

(108) Sc II, CCHR 43, 126, 66-70: Vnde numquam obliuiscatur homo me solum Deum in his tribus personis inuocare, quia eas propterea ostendi homini, ut homo tanto acutius in amore meo ardeat, cum propter amorem eius misi Filium meum in mundum, quemadmodum Iohannes dilectus meus protestatur dicens.

(109) Sc II, CCHR 43, 126, 71-127, 110. 
d) La "inteligencia" de las tres personas divinas en la unidad de ser.

Sc II, 5-8 trata el contenido de tal peculiar "inteligencia ardiente" como se trasluce primero en los tres símbolos (110): la piedra (111), la llama y el verbo. Dichos símbolos luego confluyen en la unidad del Verbo, síntesis de una "racionalidad ardiente"-Ep (112). De todos modos, emerge una intelección enraizada en el amor, en su índole triple y una.

En los tres símbolos trasunta el vigor, fulgor y sonido del hablar inefable del Padre en su paternidad. En consecuencia, es incuestionable la consistencia del Hijo en su filiación, pues manifiesta el vigor, la inteligencia y la fuerza. Por su parte el Espíritu Santo asciende e ilumina a los hombres. Finalmente Dios es amor en su totalidad, pero mientras el Padre es su origen fontal, y el Hijo lo concreta a través de la salvatio caritatis (113), el Espíritu Santo se identifica con Él en cuanto materna dilectio amplexionis (114), siendo su ardor el que hace arder, en una paradoja de movimiento y reposo.

Esta compenetración entre inmanencia y misión se conserva, sin duda, en la unidad a través del único suceso del habla, pero se bifurca en la procesión inmanente y en la encarnación. El hablar -Verbo- involucra a Dios en su totalidad. En cuanto el Padre habla, es sonido; el Hijo es Verbo propiamente tal, que le da su consistencia, pero en el Espíritu Santo, que completa esta "racionalidad" por su ardor que hace arder.

Tras tal tejido nítido de relaciones que se fundan mutuamente al completarse en la inteligencia, a la cual exhorta, la visión se concreta no solo por la actividad de cada una de la tres personas para con el hombre, sino que desembocan en la compenetración de las dimensiones antropológico-teológicas propiamente tales.

\section{e) La compenetración perijorética de intellectus y amor}

Sc II, 9 no solo verifica la compenetración de las tres personas en la misma estructura antropológica del ser humano, sino que las explicita a través de la dinámica del tiempo y de la história, tanto universal como individual (115).

En efecto, la inteligencia de la mente, en primer término, anuda las tres etapas de creación, caída y vivificación para una simultaneidad circular del "ya y todavía no". La misma compenetración atestigua, luego, el crecimiento personal en forma de ascenso a través de sus tres etapas de purgación, iluminación y unión. Finalmente, la exhortación (116) que incita a dar cumplimiento al ardere a través del intelligere en

(110) Sc II, CCHR 43, 127, 110-184.

(111) GÖSEBRINK H. M., "So leuchter der befreite Mensch in Gott und Gott im Menschen. Edelsteine als Symbole des Heils bei Hildegard von Bingen, GuL71 (1998) 346-361.

(112) Ep XLVII, PL 197, 230A: Deus quosque igneam rationalitatem animae...immisit, pero quod in carne et sanguine velut cibus per ignem confortatur et solidatur. Cf. KERN U., o.c., 21.

(113) Sc II, CCHR 43, 127, 99.

(114) Sc II, CCHR 43, 127, 87

(115) Sc II, CCHR 43, 131, 204-233.

(116) Sc II, CCHR 43, 132, 234-236: Sed qui uigilantibus oculis uidet et sonantibus auribus audit, hic mysticis uerbis meis osculum amplexionis praebeat, quae de me uiuente emanant. 
el amplexus vuelve al sensus en su distinción tripartita de vidit, audit, para abrazar, luego, lo recibido por el el osculum amplexionis.

En síntesis, intellectus y amor se compenetran gracias a los sentidos abiertos a la realidad del mundo. El cuanto más del Quien es su Creador, que la autora evoca con la misma positividad con que Gregorio Magno se refiere al Dios bíblico. Tal intelección, ligada a los sentidos, es trascendida por la Visión, acontecimiento complejo y dinámico, inverso a Eriúgena -en lo que se refiere a la implicaciones sobre el sujeto-, con quien la autora comparte las etapas del ascenso, purificación, iluminación y unión al modo dionisiano. Más allá de la intelección, la visión activa, el recuerdo y el amor, en forma de imperativo objetivo, histórico -no como proceso del propio pensar subjetivo-, el amor revela la misma índole práctica que tiene en Anselmo.

\section{3) AMOR IPSE INTELLECTUS EST, SEGÚN GUILLERMO DE ST. THIERRY.}

Guillermo, pensador profundo y genial del siglo XII (117), difícil de ubicar en su contexto histórico y siempre a la sombra de su amigo Bernardo (118), plantea el problema de la razón y el amor con gran complejidad, de modo que dicho problema queda lejos de ser solucionado, pese a numerosos estudios destinados al análisis de dicho problema (119).

a) Razón y amor en mutua colaboración según "De natura et dignitate amoris” 21.

El célebre texto de la obra guillerminiana temprana compara la razón y el amor con dos ojos, cuando aborda la visión de Dios cual alma creada por Dios, visión que consiste en la caridad (120). Se trata, sin duda, de un antiguo símil, que resalta la complementación de la razón y el amor para llegar a ser "un único ojo" (121). El

(117) Cf. H. URS VON BALTHASAR, Einleitung, Wilhelm von St.Thierry, Der Spiegel des Glaubens (Christliche Meister, 12) Einsiedeln 1981, 11-14.- quien cita a L. Bouyer Guillermo de Thierry, en latín Guillelmus a Sanctus Theodoricus.

(118) Cf. J. DECHANET, Guillaume de Saint Thierry, 61-97. - Guillermo se refiere a la "luz de Oriente"en su Epistula de Oro 1 (SC, 223) 144. Retoma la tradición alejandrina de Orígenes y de los capadocios. Se hace notar también un trato benévolo de la filosofía pagana, griega, sobre todo, de Platón y Plotino, por lo cual se suele hablar del "platonismo del siglo XII". - Pero Guillermo es capaz de entretejer ambas tradiciones de tal modo que surge algo nuevo Cf. M. ROUGE, Doctrine et expérience de l'eucaristie chez Guillame de Saint-Thierry (Théologie Historique, 111) Paris 1999, 7. n 2., Guillermo llegó a ser objeto de una especie de "Guillelmologie".

(119) Cf.J. LECLERQ, Etudes récentes sur Guillaume de Saint-Thierry, Bulletin de philosophie médiévale, 19 (1977); M. ROUGE, Doctrine et expérience de 1'eucaristie chez Guillame de SaintThierry (Théologie Historique, 111) Paris 1999; Ruh K., Amor deficiens and Amor desiderriiin der Hohenliedauslegung Wilhlems von St.Thierry, Ons Geestelijk $63 / 64$ (1989-1990) 70-88. - La cronología de las obras de Guillermo. No está fijada definitivamente. De hecho está relativamente poco estudiado el asunto.

(120) DA 21 Visus ergo ad videndum Deum naturale lumen animae, ab auctore naturae creatus, caritas est.

(121) DA 21 Sunt autem duo oculi in hoc visu, ad lumen quod Deus est videndum naturali quadam intentione semper palpitantes, amor et ratio. Cum alter conatur sine altero, non tantum [al. adeo] proficit; cum invicem se adjuvant, multum possunt, scilicet cum unus oculus efficiuntur, de quo dicit sponsus in Canticis: Vulnerasti cor meum, o amica mea, in uno oculorum tuorum (Cant. IV, 9). RUH K., Die Augen der Liebe bei Wilhelm von St.Thierry, TZ 45 (1989) 103-114. 
autor desglosa los detalles del proceder de la razón y el amor como un innegable esfuerzo, lo que permite apreciar aspectos significativos de índole no solo peculiar sino, incluso, paradójica.

Sin duda, ambos "ojos" se orientan hacia la visión de Dios, pero mientras la razón puede ver a Dios solo en aquello que no es, el amor descansa en lo que Dios es. La razón, entonces, se contenta con lo que Dios no es, una delimitación un tanto magra, a primera vista, pero que entraña todas las posibilidades que Dionisio Areopagita logró poner de relieve (122). Afirma el texto: "por los caminos determinados tiene sus señales trazados" (123); por ellos avanza obteniendo positivamente resultados, pues avanza de lo que no es a lo que es.

El amor, a la inversa, avanza más "por aquello que carece" y "aprende más por lo que ignora" (124). Al igual que a la razón, deja atrás lo que no es, pero goza en lo que no es. Este gozo respecto de su propia carencia no indica el paso sucesivo de un estado a otro (125). Pero ¿a qué apunta este defectus y el deficere?

Todo depende de cómo entender este defectus, a fin de comprender la ayuda mutua entre la razón "de mayor sobriedad", y el amor, de una "felicidad más grande". Esta ayuda se describe como "un instruir la razón al amor" y "el amor a la razón" y esto de tal modo que, "la razón cede ante el impulso del amor y el amor acepta ser mantenido en los límites de la razón”. Solo así ambos pueden realizar algo grande.

Pero cabe preguntar cuál es la condición fundante de este "ceder el paso la razón" y de aquello que afirma que "el amor, dejando tras sí lo que no es, goza abismarse ante lo que es" (126). ¿Qué es lo que les permite a ambos "aspirar naturalmente a volver a su principio” (127)? ¿No estarán en juego aspectos cristológicos y pneumatológicos, o incluso kenóticos?

\section{b) La intelección kenótica a partir del "sentir de Cristo", según Med III.}

Todo la Meditación III - un comentario de Ex 33, 20: "nadie puede ver a Dios y seguir viviendo" (128),- trata de explicar la relación entre amor y conocimiento por medio de 2 Co 13, 12 y Mt 11, 25-27 a partir del deseo profundo de ver a Dios, que desemboca en un "comprender no comprendiendo" (129).

Resalta, en primer lugar, la importancia del breve análisis del conocimiento físico -intellectus physicus-. Todo sensus corporeus, para que sea sentido y sienta,

(122) La influencia de Dionisio Areopgita puede apreciarse, sobre todo, en las Meditaciones, pero está omnipresente en toda la obra guillermiana.

(123) DA 21, PL 184, 393B: Habet etiam ratio suos quosdam tramites certos, et directas semitas quibus incedit: In tantum enim solummodo potest invenire quid est, in quantum invenit quid non est.

(124) DA 21, PL 184, 393B: amor autem suo defectu plus proficit, sui ignorantia plus apprehendit.

(125) Así lo defiende un estudioso de tanta calidad como Verdeuyen VERDEYEN P., La Theologie Mystique de Guillaume de Saint-Thierry, Paris 1990.

(126) DA 21, PL 184, 393B: amor postponens quod non est, in eo quod est gaudet deficere

(127) DA 21, PL 184, 393BC: Inde quippe processit; et naturaliter in suum spirat principium.

(128) Med III, SC, 324, Stans autem coram te sicut pauper, mendicus et caecus, sicut tu vides me non videntem te, plenum desiderio tuo pectus, totumque me quidquid sum, quidquid possum, quidquid scio, et hoc ipsum quod post te langueo et deficio, offero tibi; sed ubi te inveniam non invenio.

(129) Med III, SC, 324, 76, 8-10: intellectu comprehendat non comprehendendo majestatem diuinae incomprehensibilitatis. 
necesita de una cierta afición sensible -sensibilia affectione- de tal modo que se transforme en aquello que siente (130). Si el alma del que siente, mediante el sentido que vincula la razón con la cosa sentida, no se cambia por una cierta transformación de sí mismo, en la cosa o cualidad de cosa que siente, no habrá sentido, ni un poder sentir (131).

Aplicado lo dicho al conocimiento de Dios, esto significa que si se siente por amor- sensus amoris- que Dios es bueno y que lo ama por ser bueno, se debe a que, participando con el afecto en el sumo bien, llega a ser buena la misma alma-efficitur (132). Este sentido del alma es transformado por el amor. El alma ama no por naturaleza, sino por afecto: siente al Señor en su bondad-Sb 1, 1 y lo conoce en el sentido consumado-Sb 6, 16-; esto es, se trata de un "sentir en vosotros lo mismo que en Cristo" -Flp 2, 5 (133). Es la caridad, mediante la cual el que ama permanece en Dios -1 Jn 4, 16 (134).

Tal "sentir de Cristo" se gesta a través de la situación del hombre en el mundo y sus enigmas. Estos precisamente llevan a la pregunta por la validez y utilidad de los sentidos, ya que ni ellos ni la razón pueden tocar a Dios (135). Pero la inteligen-

(130) Med III, SC, 324: Quod ut aliquantum nobis dilucidius pateat, de visu et naturali ejus potentia videndum est, quid habeat physicus intellectus. Omnis [Col. 0213B] sensus corporeus, ut sensus sit et sentiat, oportet ut quadam sensibili affectione aliquomodo mutetur in id quod sentit; visus scilicet in hoc quod ei fit visibile, auditus in audibile; sicque de reliquis. Alioqui nec sentit, nec sensus est. Nisi enim rem sensam, sensu rationi renuntiante, anima sentientis quadam sui transformatione mutetur in rem,

(131) Med III, SC, 324: vel rei qualitatem quae sentitur; nec sensus est, nec sentire potest.

(132) Med III, SC, 324 Ubi es, Domine, ubi es? Et ubi, Domine, non es. Scio certe et certe certus sum quia hic modo mecum es, in quo movemur et sumus; et ex cujus saluberrima praesentia ardet et deficit in salutare tuum anima mea. Scio certe verissime, sentio saluberrime, te esse mecum; scio et sentio, adoro, et gratias ago.

(133) Med III, SC, 324: Ideoque si sentit, amore qui sensus suus est, Deum bonum; et amat, quia bonum: non hoc potest, nisi bono ipsi affectu communicans, et ipsa bona efficiatur. Si ad sensum animae revertatur, nonne hoc est, quod Paulus dicit: Gloriam Domini speculantes, in eamdem imaginem transformamur? [Col. 0213C] (II Cor. III.) Sic enim est quodammodo de sensu animae. Sensus enim animae amor est: per hunc sive cum mulcetur, sive cum offenditur, sentit quidquid sentit. Cum per hunc in aliquid anima extenditur, quadam sui transformatione in id quod amat transmutatur: non quod idem sit in natura, sed affectu rei amatae conformatur, utpote non bonum aliquem amare potest, quia bonus est, nisi et ipsa in ipso bono bona efficiatur. Nonne hoc est: Sentite de Domino in bonitate? (Sap. I.) Et Sapientia: Scire enim te, sensus est consummatus (Sap. VI). Et Apostolus: Hoc sentite in vobis, quod et in Christo Jesu (Philip. II).

(134) Med III, SC, 324: Haec est caritas, qua qui diligit, in Deo manet, et Deus in eo (I Joan. IV). O caritas, caritas, quae usque huc nos adduxisti, ut, amando Deum, et Filium [Col. 0213D] Dei, dii et filii et Dei nominemur et simus. Etsi nondum apparet, quod erimus, cum apparuerit, similes ei erimus: quia videbimus eum sicuti est (I Joan. III).

(135) Med III, SC, 324: Domine, bonum est nos hic esse; libet hic immorari; et utinam liceret immori! Sed meditantibus et loquentibus et scribentibus de te, da, quaeso, sensus sobrios, verba circumcisa et disciplinata; cor ardens de te, o Jesu, in apertionem Scripturarum, quae de te sunt. Ignosce, Domine, ignosce; amor amoris tui agit me; tu scis, tu vides. Non sum scrutator majestatis tuae, sed pauper gratiae tuae. Obsecro te per dulcedinem tuae dulcissimae mansuetudinis, non opprimat me majestas tua; sed sublevet gratia tua. Ignosce, inquam, quia proprium est fidei desiderium visio Dei: hic in aenigmate, ibi vero facie [Col. 0214A] ad faciem. Non enim praesumas, neque confidas, o homo, neque hic stes, quisquis vir desideriorum es, sicut Daniel; nec dicas, sufficit. Quidquid hic de Deo sentis, quidquid vides, quidquid de eo hic te docet fides, aenigma est: aliud quidem obscurius, aliud autem expressius. Et ipsum tamen quam dulce sit, cum adest; quam desiderabile, cum videtur deesse; sciunt, qui sentiunt. Hic est enim calculus habens nomen scriptum, quod nemo scit, nisi quia accepit (Apoc. II). 
cia que viene de "lo alto" -Stgo 3, 17-, trae consigo las razones: el Espíritu Santo sobrepasa lo no es Dios. De tal modo, el ser humano, "de repente" se transforma en otro hombre y "comprende no comprendiendo", gracias al "gustar y ver cuán suave es el Señor" (136).

\section{c) El "sentido encendido por el amor", según Med VII}

Todo se centra en el deseo de la visión de Dios-Sal 26, 8-9. Pero surge la pregunta, ¿es posible la visión del rostro de Dios en esta vida? Las respuestas de Guillermo son claras: según Ex 33, 20 no, pero sí hay otra visión, la docta ignorantia (137).

Sin duda, la respuesta de la Med VII, 7 es tajantemente un no. Por eso, es mejor saber ignorando, como ya lo afirmó Med III, 12. Sin embargo, la explicación de Guillermo, que ignora Ex 20, 21, reconoce otra vía, que se realiza por "el sentido iluminado por el amor".

Lo expuesto recibe aquí una notoria complementación a partir de la interpretación de Ex 25, 40, de uso muy frecuente en la obra guillerminiana. Esta cita no solo acentúa la posibilidad de conocer a Dios, a través de la Encarnación (138), sino insiste que son algunos, los santos, que han alcanzado esta visión ahora y comparten su experiencia iluminada incondicionalmente con otros en la "comunión de los santos" (139). Esta dimensión eclesial explicita "lo de lo alto" en su índole colectiva práctica para afirmar la posibilidad concreta de conocer a Dios (140).

De esta manera, el texto responde en forma afirmativa a la pregunta de si la contemplación de Dios es posible en esta vida, porque dicha contemplación es amor. Se produce ya en esta vida aquello que en la vida futura es luz y fuego, un conocimiento supereminente. Sin embargo en esta vida persiste el interim (141).

(136) Med III, SC, 324, et Trinitas unitatis, [Col. 0214D] ut pio et sobrio intellectu comprehendat non comprehendendo majestatem divinae incomprehensibilitatis. Sicque gustans et videns quam suavis est Dominus, repente sic totus gustando dulcedinem ejus dulcescit, sic vivendo lucem veritatis ejus lucescit; sic de repentina summi boni plenitudine in gaudio S. Spiritus exhilarescit, ut si hoc in eo perficiatur, confidat se vitam obtinuisse aeternam. Haec est enim, inquit, vita aeterna, ut cognoscant te solum verum Deum, et quem misisti, Jesum Christum (Joan. XVII). Accedite ergo ad eum, et illuminamini; et facies vestrae non confundentur (Psal. XXXIII).

(137) Med VII, SC, 324 Est quidem alia facies, et alius vultus notitiae tuae, de qua dictum est ad Moysen: Facies mea non videbitur tibi: non enim videbit me homo et vivet (Exod. XXXIII): visio vel scientia divinae majestatis tuae, quae in hac vita melius nesciendo scitur, et scire aliquem, quomodo eam nesciat, haec in hac vita summa ejus scientia est.

(138) Med VII, SC, 324Sic et tu, o sapientia Dei et lux veritatis, cum venisti in mundum, per quem mundus factus est, illuminasti [Col. 0229B] omnem hominem venientem in hunc mundum; sed tenebrae te non comprehenderunt. Quotquot autem te receperunt, et lucem veritatis tuae, dedisti eis potestatem filios Dei fieri.

(139) Med VII, SC, 324, Sed, o Domine, licet tenebras ignorantiae nostrae et caecitatis humanae posueris latibulum faciei hujus; tamen in circuitu tuo tabernaculum tuum, luminosi scilicet tui, sancti aliqui fuerunt, qui de luminis et ignis tui contubernio lucentes et ardentes

(140) Med VII, SC, 324 verbo et exemplo caeteros illuminabant et accendebant, et hujus supereminentis notitiae tuae solemne gaudium in futura nobis [Col. 0229A] vita denuntiabant, qua videberis sicuti es, vel facie ad faciem:

(141) Med VII, SC, 324, interim vero per eos fulgura veritatis tuae alluxerunt orbi terrae, et illuxerunt coruscationes, ad quas hilarescunt, qui sanos habent oculos; commoventur autem et conturbantur, qui diligunt tenebras magis quam lucem. Sic interim, o visu desiderabilis! exquirit te facies mea; faciem tuam requiro, ne, obsecro, avertas eam a me (Psal. XXVI). Sed doce me interim, o aeterna 


\section{d) La transposición a "Cristo en la conscientia” por el afecto}

La Med X se centra en la humanidad de Cristo y la contemplación de su encarnación, condensada en la "imagen de la pasión", que en el silencio profundo revela hasta qué punto dicha imagen es expresión del amor que Dios nos tiene (142).

Esta contemplación de la pasión produce, luego, un traslado, "de súbito", al afecto del bien eterno, cuyo rostro es la obra de la salvación (143), Es decir, no se alcanza conocer a Dios como consecuencia "de un esfuerzo humano de la inteligencia", ni "a modo de una vibración de los ojos del alma que destilan luz", sino "en el apacible sentido del amor y el buen ejercicio de ver y gozar la suavidad", gracias a la sabiduría que ordena dulcemente todo nuestro amor (144). Emerge aquí, la conocida secuencia: amor-conocimiento-fruición.

Insiste el texto en que el señalado es el único camino auténtico; cualquier otro produce fatiga. Solo Cristo es el acceso al Padre, la única puerta. Entonces, ya no se trabaja con el conocimiento de "una ciencia supraemiente", sino que todo se resuelve en la suavidad de la conciencia, enteramente "tocada" (145). Ella permite ver a Dios como es-1 Jn 3, 2. De este modo, se produce la preparación para el ascenso a Dios. El paso siguiente está orientado hacia la similitudo con el Padre, Hijo y el Espíritu. Por el Espíritu, el afectado asciende a Dios.

\section{e) El amor en cuanto intellectus en la “unidad del Espíritu”, según ExpCant.}

El texto de ExpCant, obra tardía, retoma el símil de los dos ojos que ejemplifican la colaboración de la razón y el amor. Ello permite apreciar la diferencia notoria que existe con respecto al texto anterior De nat et dign 21. No solo razón y amor invierten su ubicación, sino que también cada una queda mejor delimitada al ámbito de "la ciencia" y de "la sabiduría" (146).

Ciencia y sabiduría se explican como "las cosas humanas" según la ciencia, en la cual se mueve la razón, mientras que la sabiduría, que es propia del amor, se inscribe

sapientia, illustratione ipsius vultus tui, quae sit ista facies et facies; quia, licet desiderio alterius ad alteram contrabescam, neutram tamen [Col. 0228A] satis novi.

(142) Med X, SC, 324, Cum enim attentius respicimus in imaginem passionis tuae silente ipsa, videris nobis dicere de cruce: Cum dilexissem vos, in finem dilexi vos. Mors et infernus mordeant me in mortem suam; comedite vos amici, et inebriamini, charissimi, in vitam aeternam.

(143) Med X, SC, 324 Mediante namque imagine passionis tuae, Christe, cogitatum a nobis circa nos bonum tuum repente nos transfert in summi boni affectum.

(144) Med X, SC, 324, Cujus faciem in opere salutis tuae das nobis videre, non jam quasi humano conatu exorta intelligentia, et trementibus oculis mentis, et refugientibus lucem tuam, sed placido amoris sensu, et bono usu videndi et fruendi suavitate, sapientia tua quae nostra sunt disponente nobis suaviter.

(145) Med X, SC, 324 Laborat enim, qui ascendit aliunde. Qui vero per te intrat, o ostium, per planum graditur, et venit ad Patrem, ad quem nullus venit nisi per te; nec jam laborat in intellectu supereminentis scientiae; sed totus resolvitur in suavitate bene affectae conscientiae.

(146) ExpCant 88, CCHR, 88, 67, 48-55: Duo sunt oculi contemplationis, ratio et amor. Et secundum quod dicit propheta: Divitiae salutis sapientia et scientia, alter secundum scientiam, quae sunt humana; alter uero divina scrutatur secundum sapientiam. Cum uero illustrantur a gratia, multum se adiuvant ad inuicem, quia et amor uiuificat rationem, et ratio clarificat amorem, fitque columbinus intuitus, simplex ad contemplandum, prudens ad cauendum. 
en el ámbito de "realidades divinas". Como en De nat et dign 21 "la razón tiene sus caminos determinados, sus senderos bien trazados por los que avanza "con mayor sobriedad", mientras que la "sabiduría" explica la"mayor felicidad "del amor (147).

Ahora, razón y amor son sostenidos y consolidados por la gracia que los "ilustra", verdad que no se menciona en De nat et dign 21. De tal modo, razón y amor se prestan entre ambos una "gran ayuda". El amor vivifica la razón -no solo la ilumina-, y la razón clarifica al amor. Por lo cual, ambos se "convierten en una mirada de paloma”, simple para contemplar, prudente para guardarse del peligro. La alusión al Espíritu Santo es innegable, pero también está presente la índole práctica de la mutua colaboración entre razón y amor.

Lo que está en juego es la compenetración entre el espíritu humano y el Espíritu Santo, subrayada por el texto, cuando insiste que los dos ojos llegan a ser un ojo en la contemplación de Dios. En la contemplación de Dios, en la cual obra ante todo el amor, la razón se transforma - transit-en amor. Este transit designa la "vuelta al origen", que es amor, explicando así el spirat in principium de De nat et dign 21, acorde con la fórmula frecuente de ExpCant, in unitate spiritus.

Gracias a este retorno al origen se da aquella "intelección espiritual y divina", que"trasciende y absorbe la razón", pero no la suprime, sino que la eleva, es decir, la ratio se hace intellectus, tal como lo sintetiza la famosa fórmula "amor ipse intellectus est”, que se remonta a Gregorio Magno, teniendo sus raíces en Gregorio de Nisa.

Sintetizando, Guillermo hace confluir dos modelos antiguos de la colaboración entre razón y amor a través del símil de "los dos ojos": el estático y el gradual dinámico del transit, que desemboca en la unitate spiritus. A través de este aporte propio el autor se permite afirmar: "somos por gracia, lo que Dios es por naturaleza". Esto significa, en definitiva, que el problema razón y amor se traslada de su articulación natural a la de la gracia.

Además de una nítida delimitación de los ámbitos y sus capacidades, Guillermo concreta la compenetración de razón y amor a través de la Encarnación, haciendo depender tanto la razón como el amor de los sentidos, los que, en cuanto "sentir de Cristo", ponen de relieve el significado kenótico de solución dada al problema razón y amor. Al respecto, se hace notar una diferencia con la visión más creacional y positiva de Hildegard von Bingen.

El defectus y el deficere del amor es, paradójicamente, no solo lo que constituye la condición de posibilidad, sino que expresa también el alcance concreto del exceso de amor. Ello permite a Eriúgena trascender a la superesencia, situación que Guillermo la percibe anticipada ya en esta tierra, gracias a la innegable dimensión eclesial concreta.

Guillermo resalta, más que los autores anteriores, el aspecto de gratuidad por el uso de la antiquísima fórmula de "lo súbito", lo cual significa asimilación profunda por la participación en la pasión de Cristo. El énfasis sobre la dimensión kenótica atestigua la índole profundamente teológica de la solución que ofrece Guillermo al problema planteado. Como tal se distancia de lo aportado por Anselmo a partir de la

(147) ExpCant 88, CCHR, 88, 67, 55-59: Fiuntque saepe duo isti oculi unus oculus, cum fideliter sibi cooperantur, cum in contemplatione Dei, in qua maxime amor operatur, ratio transit in amorem et in quendam spiritualem vel diuinum formatur intellectum, qui omnem superat et absorbet rationem. 
creación, pese a que tiene indudablemente mucho en común con el obispo de Canterbury, debido a la influencia agustiniana que les es común.

De todos modos, no cabe reducir el aporte más original de Guillermo a la solución del problema razón y amor a la insistencia kenótica. Esta profunda verdad cristológica, recién revela toda su hondura cuando el autor acentúa esta dimensión por un genial énfasis pneumatológico, es decir, por el in unitate spiritus, una racionalidad interpelada por la máxima paradoja de un amor kenótico y una razón, que desfallece... transformándose en vida.

Para Guillermo la transformación del conocimiento en amor atestigua una presencia activa del "otro", quien, en calidad de presencia desde fuera, inhabita la profundidad más íntima del "sí mismo", "su conciencia", de modo siempre nuevo y plenificador por Cristo -el Hijo amado- en el Espíritu Santo. Recién a la luz de esta presencia y la reciprocidad personal trinitaria se explica, por qué el conocimiento y el amor se compenetran, existiendo uno en el otro. El hombre participa en esta inexistencia perijorética por gracia, cuando llega a ser lo que Dios es por naturaleza.

\section{4) LA RACIONALIDAD DEL CON-DILECTOR, SEGÚN RICARDO DE SAN VÍCTOR}

Ricardo de San Víctor, pensador original y fecundo de la temprana Edad Media (148) y el mejor biblista del s. XII (149), con un vocabulario de gran elasticidad, ejerce su actividad intelectual en un contexto marcado por la regla agustiniana, centrada en el amor de Dios y al prójimo (150). La influencia dionisiana recibe desplazamientos teológicos notorios (151). El problema razón y amor es tratado por casi todos los estudios que se dedican a tal "obra abundante y dispar" (152). Un acceso a la estructura del pensamiento del autor ofrece la firme convicción de la validez de la razón y de sus "razones necesarias" (153). Sin duda, emerge aquí un

(148) Cf. DUMEIGE, G., Richard de Saint -Victor et l'idee chretienne de l'Amour, Paris 1952, 7.

(149) CHATILLON J., Richard de saint, DSp 628. -Para la influencia de Gregorio Magno cf. ARIS MA., Contemplatio. Philosophische Studien zum Traktat Benjamin Maior des Richard von St. Victor (Fuldaer Studien, 6) Frankfurt 1996, 36 y 96.

(150) Cf. ARIS M-A., o. c., 8.

(151) Cf. DUMEIGE G., 113, n.73: Cf. Apoc I, 1 (687 A) La definición que da el Pseudo-Dionysius: "Symbolum est collectio formarum visibilium ad invisibilium demostrationem" sobre todo, la teología trinitaria de Ricardo revela mayor presencia de Agustín en cuanto a su dinámica profunda relacional y solo la idea del exceso de bondad hace recordar a Dionisio. Es significativo también, además, el concepto de símbolo, propia de Dionisio que Ricardo integra. Cf. DEN BOK N., Communicating the most high. A systematic study of person and Trinity in the theology of Richard of St. Victor (+ 1173) (Bibliotheca Victorian, VII) Paris-Turnout1996, 112 n.65 y 163 , n.53: los vestigios de la Trinidad de la creación, que los victorinos, incorporando al Areopagita.cf. GONZALEZ O. Sobre las fuentes de Ricardo de San Víctor y su influjo en San Buenaventura, La Ciudad de Dios 176 (1963) 567-602.

(152) RICHARD VON ST.VIKTOR, Die Dreieinigkeit, Übertragen und Anmerkungen von Hans Urs von BALTHASAR, Ensiedeln 1980, 15ss. Cabe destacar la obra clásica de G. Dumeige y los estudios de M. Arias Reyero, sobre todo, "Al principio amaba el amor". La doctrina de la Trinidad en Ricardo de San Víctor, TV 31 (1990) 163-190;

(153) De Trinitate, Prólogo: "Nos debe parecer poco creer lo que es verdadero y recto de Dios; trabajemos, como se ha dicho, para entender lo que creemos. Empleemos siempre, en cuanto puede ser 
concepto nítido de la razón, interrelacionado con los sentidos, la imaginación y la inteligencia. Pero cabe preguntar cómo se integra en tal convicción el amor.

\section{a) La tensión "semejanza y desemejanza" como ritmo oscilante del problema razón y mor, según BenMay IV 8 y 9.}

El Libro IV del famoso tratado BenMay está centrado en la interpretación alegórica del "arca mística" de Moisés -mysticam Moysi arcam-, que designa los secretos divinos, Cristo. Los capítulos 8 y 9 de ese tratado explican el problema razón y amor a la luz de los dos querubines colocados encima del arca (154). Ellos simbolizan los géneros cinco y seis de la contemplación, distintos de los géneros uno a cuatro, que el autor analiza, previamente, según el programa esbozado en BenMay I 6 (155). Si ambos querubines se miran, esto quiere decir que hay colaboración entre ellos, pero se distinguen en la ejecución de su función, orientada por "la semejanza" y "la desemejanza" y anticipada por la gracia (156).

En efecto, el querubín de la derecha, revela el quinto género de contemplación super rationem, pero no praeter rationem. La razón, característica propia de la criatura creada a imagen y semejanza de Dios, asciende desde lo semejante hacia lo desemejante para sacar conclusiones profundas respecto de lo desemejante, que no puede alcanzar por propia cuenta, sino que por la fe en la autoridad de la Sagrada Escritura (157). La semejanza, el ámbito de la substancia racional, es más fácil de "investigar, confirmar y adaptarse", que la desemejanza, que apunta a la "esencia de la suma divinidad" (158).

Por su parte, el querubín de la izquierda, tiende por naturaleza a lo oculto. Su actividad es más difícil de captar cuando la inteligencia se eleva hacia aquello más desemejante, donde no existe ningún esbozo de semejanza (159). Representa el

lícito y posible, por comprender con la razón lo que tenemos por la fe.” cf. ARIAS M., Fe y razón: las razones necesarias en el "De Trinitate" de Ricardo de San Víctor, TV 32 (1991) 295-310;

(154) BenMay I, 1 PL 196, 63 B: Mysticam Moysi arcam libet, si liceat ex inspirationis illius munere qui habet clavem scientiae lucubratiunculae nostrae expositione, vel ad aliquid reserare, et si quid adhuc in hoc arcanorum divinorum secretario, scientiarumque reconditorio repositum latet... Quid juxta allegoricum sensum haec arca mystice designet, vel quomodo Christum significet, a doctoribus fuit jam ante nos dictum et a perspicacioribus pertractatum. Cf. ARIS M-A., o. c., 96ss.

(155) BenMay I, 6 PL 196, 70B-72C. -Quot sint vel quae contemplationis genera. Sex autem sunt contemplationum genera a se et inter se omnino divisa. Primum itaque est in imaginatione et secundum solam imaginationem. Secundum est in imaginatione secundum rationem. Tertium est in ratione secundum imaginationem. Quartum est in ratione et secundum rationem. Quintum est supra, sed non praeter rationem. Sextum supra rationem, et videtur esse praeter rationem

(156) BenMay IV, 8, PL 196, 112A: Quaeramus igitur quae sint ista duo propitiatorii nostri latera, ut consequenter inveniamus quo unus ex cherubin stare habeat ex parte una, et alter ex altera. Sicut superius jam satis ostendimus, per propitiatorium illud contemplationis genus intelligimus quod habetur de spiritibus rationalibus. Cf.ARIS M-A., o. c., $61 \mathrm{ss.}$

(157) Cf.ARIS M-A., o. c., 56.

(158) BenMay IV, 8, PL 196, 112D: Dicatur itaque propitiatorii nostri, si placet, latus unum, divina in rationabilibus substantiis similitudo, dicatur et alterum in eisdem essentiis Divinitatis summae multiplex dissimilitudo.

(159) BenMay IV 9, PL 196, 114C-114D: Nam quidquid divinum simile, vel divinis dissimile in nobis cernitur, divinorum, uti jam dictum est, comparatione fuscatur. Solet autem, ut diximus, obnubilatio non solum claritatem, verum etiam calorem temperare, et utrumque tolerabiliorem 
sexto grado de la contemplación, que es supra rationem y praeter rationem. Ocurre aquí el fenómeno de ocultamiento en sus dos facetas, la de ocultar y la de proteger, contra el calor y la claridad. En este punto, después de tanto esfuerzo y deseo, "somos raptados", de tal modo que la mente queda en suspenso, no sabe cómo, y solo el amor vale (160).

Pese a la mutua colaboración entre razón y amor por un constante reforzamiento de la razón, ella cede el paso al amor, explícitamente, en el último grado de la contemplación, donde se trata de afinar la relación entre semejanza y desemejanza, en forma explícita, como sucede al final de IV 9 (161). Al respecto Ricardo señala como ningún espiritu racional está privado del amor de la excelencia suya y la aprobación del mundo. Pero la contemplación de la esencia creadora y la supereminencia modera en cada uno ese amor y su aprobación (162).

\section{b) El "tender hacia otro", verificación indispensable de la caridad, iluminada por la razón, según De trinitate III, 2.}

Cuando en la parte III del tratado De Trinitate, a través de un desarrollo significativo del concepto de Dios en cuanto exceso de bondad, que hace recordar a Dionisio, Ricardo recurre al célebre enunciado de Gregorio Magno, "la caridad no es posible, sino entre dos", entonces, se hace visible la índole propia del amor (163), que encamina el problema razón y amor hacia una solución adecuada, que se fundamenta en la Trinidad inmanente.

Con impecable lógica, Ricardo de San Víctor aborda las "razones necesarias" para su afirmación tajante: Dios, como Sumo Bien, para la perfección de Su Amor

reddere. Et fit saepe (quod omnes novimus) ut in nostra gratia nosmetipsos aestimatione, vel dilectione modum tenere nesciamus. Sed ex divinarum utique rerum assidua contemplatione, profundaque admiratione, in nobis agitur ut utriusque in nobis nimietas vel superfluitas reprimatur. Nullum omnino, nullum, inquam, omnium rationalium spirituum, credo privatum illum propriae excellentiae amorem, vel opinionem ad veram et legitimam aequitatis mensuram posse restringere, nisi qui veraciter seipsum novit in eorum quae diximus comparatione despicere.

(160) BenMay IV, 9, PL 196, 114A-114B: Utinam cum tanto studio et desiderio, in eorum aspectum raperemur, et in eorum admiratione, cum tanta animi abalienatione, supra nosmetipsos duceremur, ut interim mens nostra seipsam nesciret, dum in ejusmodi cherubin aspectum suspensa stuperet, in tantum ut cum Apostolo dicere auderet: Sive in corpore, sive extra corpus, nescio, Deus scit (II Cor. XVIII). Vide quam profunde sub dictorum cherubin alis lateat, qui seipsum interim ignorat. Sed si non potest haec alarum adumbratio mentis respectum in ejusmodi excessus abalienare, debet tamen, quod et semper solet, aureum illum propitiatorii fulgorem obnubilare, et nostris aspectibus temperare. Propitiatorii nostri fulgor absque dubio superducta obumbratione obnubilatur, quando quidquid in nobis lucere videtur, majoris et supereminentioris claritatis comparatione despicitur.

(161) BenMay IV, 9, PL 196, 114D: Et nota quod quemadmodum arca propitiatorio tegitur, sic et ipsum propitiatorium dictarum alarum expansione tegi jubetur. Absque dubio sicut ex contemplatione spiritalis creaturae ejusque eminentiae obducitur amor et approbatio mundi,

(162) BenMay IV, 9, PL 196, 114D: sic ex contemplatione creatricis essentiae ejusque supereminentiae temperatur apud unumquemque amor et approbatio sui.

(163) De Trinitate III, 2, SC, 63, 168 : Ubi autem totius bonitatis plenitudo est, vera et summa caritas deesse non potest. Nihil enim caritate melius, nihil caritate perfectius. Nullus autem pro privato, et proprio sui ipsius amore dicitur proprie caritatem habere. Oportet itaque ut amor in alterum tendat, ut caritas esse queat. Ubi ergo pluralitas personarum deest, caritas omnino esse non potest. -Según ARIS M-A., o. c., 117 es notorio el cambio que realiza aquí Ricardo con respecto de Agustín. 
requiere del "otro"- amor in alterum tendat-. Este "otro" tiene que ser "condigno" y "consorte", es decir, Dios mismo.

En efecto, Dios Uno ama a la criatura con "caridad", pero esta no es una "caridad ordenada". Pues, la criatura no constituye un "otro digno", pues carece de la dignidad de ser Dios. Como tal no es un "consorte igual". Aquí, Ricardo refuta la enseñanza de Abelardo.

La conclusión de Ricardo es tajante y convicente: "para que la caridad sea suma y perfecta, tiene que ser de tal naturaleza que no puede ser mayor ni más perfecta, sino que requiere una "persona condignata". A esta conclusión, referida al consorte digno y divino, accede la "razón con facilidad". Esto, afirma el autor, concluye "la razón con facilidad" respecto del consorte digno y divino (164).

\section{c) El con-dilector, condición de posibilidad personal y trinitaria de la compenetración razón y amor, según De trinitate III, 19.}

Al culminar la argumentación en III 19 (iniciada en III 11ss respecto de la necesidad de un con-dilector en Dios), emerge, a través de la apretada síntesis, la evidencia racional de que el con-dilector constituye la condición que hace posible la compenetración de razón y amor (165).

En efecto, más allá del otro, la plenitud de gozo en Dios requiere un tercero, condigno y consorte. Si uno regala amor a otro, y lo ama, en forma solitaria, no existe con-dilectio (166), como tampoco, cuando dos se aman mutuamente. En este caso existe por ambos lados dilectio, pero no con-dilectio (167); De condilectio solo se habla donde un tercero, tertius, es amado por los dos, cordialiter, socialiter, y cuando los afectos de los dos confluyen en el tercero como en una llama de su amor (168).

Luego, Ricardo analiza detenidamente las implicaciones de la necesaria condilectio, que emerge entre el Padre y el Hijo, pues la condilectio faltaría en Dios, si junto con los dos no existiera un tercero. No hablamos de cualquier dilectio, sino de la suma condilectio, de la cual la criatura no es digna (169). Ricardo se pregunta:

(164) De Trinitate III, 2, SC, 63, 168: Ut ergo in illa vera divinitate plenitudo charitatis possit locum habere, oportuit aliquam divinam personam personae condignae, et eo ipso divino consortio non carere. Vide ergo quam de facili ratio convincit quod in vera divinitate pluralitas personarum deesse non possit. Certe solus Deus summe bonus est. Solus ergo Deus summe diligendus est. Summam ergo dilectionem divina persona exhibere non posset personae quae divinitate careret. Plenitudo autem divinitatis non potuit esse sine plenitudine bonitatis. Bonitatis vero plenitudo non potuit esse sine caritatis plenitudine, nec caritatis plenitudo sine divinarum personarum pluralitate.

(165) De Trinitate III, 19, SC, 63, 208: Quod de Trinitatis assertione multiplici rationis attestatione probatum est compendiosa satis multumque perspicua consideratione confirmari potest. Virtutem itaque ac proprietatem condilectionis diligenti consideratione perpendamus, et citius inveniemus quod quaerimus.

(166) De Trinitate III, 19, SC, 63, 208: Quando unus alteri amorem impendit, et solus solum diligit, dilectio quidem est, sed condilectio non est.

(167) De Trinitate III, 19, SC, 63, 208: Quando duo se mutuo diligunt, et summi desiderii affectum invicem impendunt, et istius in illum, illius vero in istum affectus discurrit, et quasi in diversa tendit, utrobique quidem dilectio est, sed condilectio non est.

(168) De Trinitate III, 19, SC, 63, 208s: Condilectio autem jure dicitur, ubi a duobus tertius concorditer diligitur, socialiter amatur, et duorum affectus tertii amoris incendio in unum conflatur.

(169) De Trinitate III, 19, SC, 63, 210: Ex his itaque patet quod in ipsa divinitate condilectio locum non haberet, si duobus tantum consistentibus tertia persona deesset. Non enim hic de qualicunque, sed 
¿quién puede explicar la suma benevolencia?, ¿en qué consiste la concordia más intima y máxima? ¿Y qué otra cosa es la condilectio, sino la confluencia de la benevolencia íntima y la máxima concordia? (170). En definitiva, el fruto de esta máxima dignidad y superación no puede faltar en el máximo bien. Por lo mismo, exige la trinidad de personas (171).

La demostración de la existencia del "tercero" en Dios, sin duda, alcanza su punto culminante en el libro $\mathrm{V}$, después de que el autor ha mostrado que el ser "persona" es aquel modo de existir, no a partir de sí mismo, sino de otro, es decir, de relaciones "opuestas" que requieren un tercero, que conecta sus extremos, en el medio -V, 5-. Esta afirmación surge cuando aborda el autor la propiedad de cada persona divina, en cuanto amor indebido-Padre-, amor debido e indebido-Hijo-y amor solo debido-Espíritu Santo-V, 19. Finalmente, Ricardo se abisma ante la propiedad del Espíritu Santo en cuanto con-dilector, de ser alguien cuya propiedad es no tener nada propio; -en V, 24-. En este punto el autor debe admitir que todo desemboca en el Misterio (172).

\section{d) La "con-figuración" de la criatura con el Espíritu a partir de la concreción del amor en relación con la razón, según De Trinitate VI, 14.}

Toda la parte VI, en su calidad de síntesis, se estima agregada al texto, prácticamente concluido con la V. parte. Ricardo, sin duda, aporta en VI, 14 un aspecto

de summa condilectione loquimur, et qualem creatura a Creatore nunquam meretur, nunquam digna invenitur.

(170) De Trinitate III, 19, SC, 63, 210: Quis, quaeso digne explicare valeat quanta virtus benevolentiae summae et usquequaque perfectae? Quis, quaeso, digne aestimare sufficiat quae vel quanta sit dignitas intimae et summae concordiae? Si tanta itaque dignitas est in his duabus virtutibus cuique ex semetipsa, quid, quaeso, virtutis, quid dignitatis inerit ubi quaevis conditur ex altera, ubi una magnificatur ex alia, ista consummatur ex illa? Quid autem aliud est intima et summa condilectio, nisi intimae et summae concordiae mutua concursio?

(171) De Trinitate III, 19, SC, 63, 210: Virtus itaque tantae dignitatis et supereminentis excellentiae sicut non potest in summo bono universaliterque perfecto deesse, sic nec potest sine personarum Trinitate subsistere.

(172) De Trinitate $V, 25, \mathrm{SC}, 63,366-368$ : Nunc igitur in unum, si placet, breviter colligamus quae in hoc libro ratiocinando exsecuti sumus. Omnibus divinis personis est commune omnem plenitudinem habere.

Commune est solis duabus omnem plenitudinem dare. Commune est solis duabus omnem plenitudinem accepisse. Commune est solis duabus non habere utrumque. Unius namque proprietas est in solo dando. Alterius proprietas in solo accipiendo. Tertiae proprietas tam in accipiendo quam in dando. Solis duabus est commune personam de se procedentem habere. Solis duabus est commune, aliunde procedere. Solis duabus commune est, non habere utrumque. Non tantummodo de se procedentem habere, est proprietas unius. Tantummodo vero procedere, est proprietas alterius. Proprietas autem tertiae tam ab alio procedere quam de se procedentem habere. Proprium est solius personae procedere a nulla. Proprium solius alterius procedere ab una sola. Proprium solius tertiae a gemina procedere. Sola autem una est a qua est nulla; sola similiter una a qua est una sola, sola vero una a qua procedit gemina.

Cum igitur sit duabus personis commune a semetipsis non esse, sed aliunde procedere, restat adhuc cum summa diligentia quaerere in quo ad invicem differant processio unius et processio alterius. Inventa autem differentia habitudinis mutuae, pro similitudinis ratione, oportet ad ultimum nomen proprium assignare. Proposueram quidem quid de his sentirem in commune proferre, sed quoniam in ipsis alta profunditas est, satius erit haec altioribus ingeniis altius discutienda relinquere; et quid, ex his quae jam dicta sunt, gratitudinis vel ingratitudinis merear, ex aliorum judicio probare. 
decisivo para la comprensión de la compenetración de la razón y del amor: el paso desde la Trinidad a la criatura, conservando y destacando la desemejanza siempre mayor entre estos términos (173).

En efecto, el amor debido es infundido en la criatura, de tal modo que ella, en su estado óntico, comparte la índole del "amor debido", propio del Espíritu Santo, al infundirse Este como don de Dios en el espíritu creado, la mente humana. Pues, ¿qué otra cosa es la donación o el envío del Espíritu Santo sino la infusión del amor debido" (174)?

El fuego de la divinidad penetra el "espíritu racional" -spiritum rationalemde tal manera que "lo inflama con el afecto del ardor del amor de Dios"- affectum divino ardore (175). Explica Ricardo: todo amor es fuego, pero fuego espiritual y "es transformado totalmente según el ser de aquel que lo inflama-similitudo transit". El espíritu humano se hace "líquido"-eliquescit, después de que se enardece, al modo del metal que se purifica, sin perder su esencia propia (176).

En definitiva, la criatura se configura con la forma kenótica del Espíritu Santo a través de una experiencia viva de ardor ardiente." Pues más -magis- por el Espíritu que por el Padre y el Hijo nos configuramos de acuerdo a la propiedad del Espíritu Santo (177). Hay así un in-esse kenótico, propio del Espíritu Santo, que impregna el espíritu humano (178).

(173) De Trinitate VI, 14 SC, 63, 412. Diligenti consideratione dignum videtur qua ratione Spiritus sanctus donum Dei dicatur. Sicut in superioribus evidenti explanatione ostendimus, in Patre est plenitudo amoris gratuiti, in Spiritu sancto plenitudo amoris debiti, in Filio plenitudo amoris debiti simul et gratuiti. -La influencia de Anselmo es notoria. Cf. GONZALEZ O., o. c, 570ss.

(174) De Trinitate VI, 14, SC, 63, 412: Quomodo autem haec omnia oporteat intelligi, satis ibi diligenter expressi. In illa vero summe simplici natura, ubi non potest esse compositio aliqua, pro certo non est aliud aliquid Spiritus sanctus, et aliud aliquid amor ipsius. Quid itaque est Spiritus sancti datio vel missio, nisi debiti amoris infusio? Spiritus sanctus ergo tunc homini divinitus datur, quando debitus Deitatis amor menti humanae inspiratur.

(175) De Trinitate VI, 14, SC, 63, 412s: Cum enim hic Spiritus spiritum rationalem intrat, ipsius affectum divino ardore inflammat, et ad proprietatis suae similitudinem transformat, ut auctori suo amorem quem debet exhibeat

(176) De Trinitate VI, 14, SC, 63, 414: Quid enim est Spiritus sanctus nisi ignis divinus? Omnis enim amor est ignis, sed ignis spiritualis. Quod facit ignis corporalis circa ferrum, hoc agit hic ignis de quo loquimur circa cor foedum, frigidum et durum. Nam ad hujus ignis immissionem, animus humanus omnem nigredinem, frigiditatem, duritiem paulatim deponit, et totus in ejus a quo inflammatur similitudinem transit. Nam ex succensione ignis divini incandescit, totus exardescit, pariter et eliquescit in amorem Dei, juxta illud Apostoli: Caritas Dei diffusa est in cordibus nostris per Spiritum sanctum, qui datus est nobis.

(177) De Trinitate VI, 14, SC, 63, 414: Sed cur, quaeso, dicitur per Spiritum sanctum, magis quam per Patrem et Filium? Sed scimus quia Pater auctorem, vel datorem non habet, unde nec nisi gratuitum amorem habere valet. Filius autem, ut superius dictum est, habet amorem tam gratuitum quam debitum. In divino itaque amore proprietati Filii, vel proprietati Patris conformari non possumus, qui simul utrumque, vel saltem solum gratuitum amorem erga Deum habere non valemus. In quo ergo, quaeso, creatura Creatorem suum gratis diligere valet, a quo habet totum quo habet? In quantum igitur auctori nostro debitum amorem reddimus, in tantum pro certo Spiritus sancti proprietati configuramur. Ad hoc namque homini datur, ad hoc illi inspiratur. ut illi in quantum sibi possibile est, configuretur.

(178) De Trinitate VI, 14, SC, 63, 416: Mittitur autem haec datio, vel datur haec missio simul et pari modo tam a Patre quam a Filio. Spiritus namque sanctus ab utroque habet totum quod habet. Si igitur ab utroque habet esse, posse et velle, merito eum dicuntur mittere, vel dare a quibus accepit, ut possit, et velit venire, et nobis inesse. 


\section{c) El” sentir con Cristo" en cuanto proyección práctica de la interrelación razón} y amor, según QGVCH IV.

El breve opúsculo De quatuor gradibus violentae caritatis aporta al problema razón y amor las líneas fundamentales de una comprensión que trasunta a través de todos los escritos de Ricardo. Estos cuatro grados están tratados en forma exhaustiva en la obra mencionada, obra que ofrece una respuesta definitiva y práctica al problema razón y amor, sintetizando lo señalado anteriormente. Bajando desde las alturas místicas del De trinitate a la concreción encarnatoria, convierte la actitud kenótica pneumática en el modo humanamente tan vulnerable del "sentir de Cristo" (179).

A través del mismo símil del metal, que se purifica -De trinitate VI, 14- el texto describe la integración del cristiano al ascenso descendente de Cristo, ligado a los sentidos. En este estado el sufrimiento de la pasión aparece como la concreción máxima del amor, cuya racionalidad solo se ilumina desde un amor extremo (180).

Esta concreción todavía adquiere mayor perfil cuando Ricardo pasa a comprenderlo como práctica del amor fraterno, según "los sentimientos de Cristo" (181).

La compenetración definitiva de razón y amor, que así se patentiza, revela su perfección y plenitud, a través del "no vivo yo, sino es Cristo Quien vive en mí" Gal 2, 20 (182).

(179) $Q G V C H I V$, PL 196, 1222AB: In tertio itaque gradu anima in Deum glorificatur, in quarto propter Deum humiliatur. In tertio gradu conformatur divinae claritati, in quarto vero conformatur Christianae humilitati. Et cum in tertio gradu quodammodo, quasi in forma Dei esset, nihilominus tamen in quarto gradu semetipsum exinanire incipit, formam servi accipiens, et habitu iterum invenitur ut homo.

(180) QGVCH IV, PL 196, 1222AB: Cum igitur anima in hunc modum divino fuerit igne decocta, medullitus emollita, penitusque liquefacta, quid jam supererit nisi ut ei proponatur quae sit voluntas Dei bona, beneplacens atque perfecta, quasi quaedam ad quam informetur consummatae virtutis, formula? Sicut enim exclusores liquefactis metallis propositisque formulis, quamlibet imaginem pro voluntatis arbitrio excludunt et vasa quaelibet juxta modum congruum formamque destinatam producunt; sic anima in hoc esse ad omnem divinae voluntatis nutum facile se applicat, imo spontaneo quodam desiderio ad omne ejus arbitrium seipsam accommodat, et juxta divini beneplaciti modum omnem voluntatem suam informat. Et, sicut metallum liquefactum quocunque ei via aperitur, facile ad inferiora currendo delabitur, sic anima in hoc esse ad omnem obedientiam se sponte humiliat, et ad omnem humilitatem juxta divinae dispositionis ordinem libenter inclinat.

(181) QGVCH IV, PL 196, 1222, BC: In hoc itaque statu animae ejusmodi proponitur forma voluntati Christi, unde et dicitur ei: Hoc sentite in vobis, quod et in Christo Jesu. Qui cum in forma Dei esset, non rapinam arbitratus est esse aequalem Deo; sed semetipsum exinanivit formam servi accipiens, in similitudinem hominum factus, et habitu inventus ut homo; humiliavit autem semetipsum, factus obediens usque ad mortem, mortem autem crucis (Philip. II). Haec est forma humilitatis Christi, ad quam conformare se debet quisquis supernum consummatae caritatis gradum attingere volet. Majorem siquidem caritatem nemo habet, quam ut animam suam ponat quis pro amicis suis.Ad summum itaque caritatis culmen profecerunt, et jam in quarto caritatis gradu positi sunt, qui pro amicis animam suam ponere, et illud Apostolicum implere jam possunt: Estote imitatores Dei sicut filii charissimi, et ambulate in dilectione sicut et Christus dilexit vos, et tradidit semetipsum pro vobis oblationem et hostiam Deo in odorem suavitatis.

(182) QGVCH IV, PL 196, 1222D-1223A: In tertio itaque gradu quodammodo mortificatur in Deum, in quarto quasi resuscitatur in Christum. Qui igitur in quarto gradu est, veraciter dicere potest: Vivo autem jam non ego, vivit vero in me Christus (Galat. II). Incipit ergo in novitate vitae ambulare qui ejusmodi est, quia de reliquo sibi vivere Christus est, et mori lucrum. Coarctatur sane e duobus desiderium habens dissolvi et cum Christo esse: multo enim melius, permanere in carne necessarium ducit propter nos. "Caritas enim Christi urget eum"; sit igitur nova creatura, qui 
En síntesis, Ricardo aporta una respuesta excepcionalmente profunda al remontar al interior de la misma Trinidad, iluminándola racionalmente desde la experiencia con las "razones necesarias", al modo de Anselmo. Tal procedimiento trasunta una fuerte influencia dionisiana, que hace distanciarse al autor de las concepciones agustinianas vigentes, tan presentes en Anselmo. Lo más significativo es el hecho de que el texto fundamental de todo el argumento del De trinitate constituye una cita explícita de Gregorio Magno, In Euan Hom XXVII, 4.

Si se pregunta por los fundamentos conceptuales que sostienen la solución estudiada en Ricardo, se debe admitir que es la reformulación tan arriesgada del concepto "persona" como ex-sistencia a partir de otro la que sirve de argumento de base, contrarrestando con ello no solo a Eriúgena, Anselmo e Hildegard, sino también enlazándose desde dentro con Guillermo de St. Thierry. Sin embargo, más original y decisivo para la solución del problema razón y amor resulta la importancia que se le asigna al con-dilector.

La con-dilectio atestigua, pues, una compenetración perijorética de relaciones opuestas, que pone de relieve la importancia de la relación para el problema razón y amor, de modo novedoso, no encontrado en ningún autor estudiado. Al destacarse la relevancia de la gracia y vista desde dentro como gratuidad por Ricardo, no solo se abre el abismo de la desemejanza en la semejanza de la criatura como condición de posibilidad para la compenetración de razón y amor, sino que se patentiza también que la solución solo será posible en cuanto donación oblativa, de tal modo que el afán de la razón posesiva se convierte en el gozo de no poseer nada.

\section{5) EL AMOR, TRASCENDENTAL POR EXCELENCIA, SEGÚN BUENAVENTURA.}

Buenaventura, un teólogo de igual magnitud que Tomás de Aquino, representa una figura aislada, en gran medida debido a su esfuerzo de retornar a la forma evangélica del saber, pues, contempla con disgusto creciente el racionalismo escolástico de su tiempo. Junto con Tomás de Aquino traza los límites entre la razón y la fe con una precisión hasta entonces no lograda, pero no como Tomás, quien asegura a la razón sus derechos' sino, por el contrario, para reducirla a sus confines, lo cual lo sitúa en una posición singularmente aislada en su tiempo.

En efecto, Buenaventura se remite al estudio fundamental de la Sagrada Escritura, y a los originalia sanctorum, siendo Dionisio una autoridad importante para su Teología de egressus y regressus a la luz del círculo inteligible, y siempre en concordancia con las fuentes latinas, sobre todo, san Agustín. Un acceso teológico al problema razón y amor ofrecen los Prólogos al Libro de las Sententias, bajo el símil de los cuatro ríos y del Hexameron y Sololoquium en cuanto interpretación de las cuatro dimensiones que enuncia Ef 3, 14-19.

\section{a) La Trinidad y los trascendentales, según "Breviloquium "I, 6” (=Brevil).}

Buenaventura parte su análisis en Brevil I, 6, asignando en profundidad al Padre la unidad, al Hijo la verdad y al Espíritu Santo la bondad, de tal modo que la 
unidad involucra eternidad, razón de principio y omnipotencia, mientras la verdad conlleva especie, hermosura, imagen, ejemplar y omnisciencia. Por su parte, la bondad apunta al uso, don, fin, voluntad y benevolencia (183). Insiste el autor: "apropiarse" no significa "adueñarse de algo con exclusión de los demás, sino conducir a la inteligentia y notitia de lo propio de las tres personas" (184).

El teólogo franciscano se acerca, entonces, desde la razón "al Principio novísimo y perfectísimo" para enunciar que la unidad es el ser en cuanto comunicable, con indivisión en sí de sí mismo, mientras la verdad lo es como cognoscible por la indivisión de sí de la propia especie, mientras la bondad es el ser "en cuanto comunicable e indivisible por su propia operación”. Debido a que los trascendentales se encuentran ordenados entre sí, suponiéndose mutuamente, la unidad, verdad y bondad designan al Padre, origen de todo; al Verbo, que procede del Padre y al Espíritu Santo, quien, a su vez, procede de ambos como amor y don (185).

Cuando Buenaventura explica los trascendentales en su interrelación con la eternidad, hermosura y utilidad para destacar la eficiencia, ejemplaridad y finalidad, concluye que estas apropiaciones insinúan el orden del egreso y regreso completo a través de la omnipotencia, omnisciencia y benevolencia. Por consiguiente, la Trinidad Suma es principalmente alabada en la Sagrada Escritura por la potencia, sabiduría y voluntad (186).

Sintetizando, en Brevil I, 6 el misterio de Dios se abre desde la razón a través de los trascendentales, apropiados a las tres personas. Ya que ellos son comunes, conducen a la inteligencia de los propios, lo cual es posible verificar por la imagen de la Trinidad en el alma de la criatura racional(Brevil II, 2, tal como en otros textos).

\section{b) La imagen de la Trinidad en el alma y el excessus amoris, según "Itinerarium Mentis "(=It) IV 3; IV 4; y VII, 4.}

En It IV 3 Buenaventura invita a "entrar en nuestra mente racional, donde reluce la divina imagen de la Trinidad" (187). Aquí se observa el alma que "se ama ardientemente a sí misma" y que "no se ama si no se conoce", y "no se conoce si no se recuerda"; es decir, con el "ojo de la razón" -oculus rationis-descubre en las tres potencias mencionadas los vestigios de unidad, verdad y bondad y conoce el ser per

ejusmodi est; vetera transierunt, et ecce nova facta sunt omnia. In tertio enim gradu mortificatus, in quarto quasi resurgens ex mortuis, jam non moritur, mors illi ultra non dominabitur, quod enim vivit, vivit Deo.

(183) Brevil I, 6, Omnia Opera V, 214 : tamen Patri dicitur appropriari unitas, Filio veritas, Spiritui sancto bonitas

(184) Brevil I, 6 Omnia Opera V, 215: Haec autem dicuntur appropriari, non quia fiant propria, cum semper sint communia; sed quia ducunt ad intelligentiam et notitiam propriorum, videlicet trium personarum.

(185) Brevil I, 6, 2 Omnia Opera V, 215: hinc est, quod haec attribuuntur primo principio in summo, quia perfecta et generalia; el appropriatur tribus personis, quia ordinata; et ideo summe unum Patri, qui est origo personarum; summe verum Filio, qui est a Patre ut verbum; summe bonum Spiritui sancto, qui est ab utroque ut amor et donum.

(186) Brevil I, 6, 5 Omnia Opera V, 215: Ex his apparet, quae sint appropriata et quibus et qua de causa. Haec tamen ultima, sicilicet potentia, sapientia et voluntas, sunt potissime illa, ex quibus in Scripturis laudatur Trinitas summa. Et ideo de his aliquid dicendum est breviter et summatim.

(187) Cf. BEIERWALTES W. Denken des Einen.Studien zur neuplatonischen Philosophie und ihrer Wirkungs- geschichte, Frankfurt a. Main 1985, 385-423. 
se, por sus propiedades en cuanto mente generadora, verbo y amor espirado. Ellos se distinguen necesariamente como producción personal. De este modo, se reconoce al Padre, al Verbo y al Amor de Dios, aunque a modo de "espejo y enigma".

Sin duda, estas "especulaciones" tienen su condición de posibilidad en la Encarnación, según It IV 4. 2. Ella, pues, permite recuperar los sentidos del oído, la vista, el olfato, gusto y tacto, de tal modo que la imagen, afectada por el Pecado Original, es restaurada por la purificación, iluminación y unión a través del "itinerario de la mente", el ascenso incesante del alma a Dios (188).

El final de tal ascenso constituye el exessus amoris en It VII, 4, el éxtasis que presenta la máxima forma de la compenetración de razón y amor, ardiendo en el fuego: Dios mismo (189). Aquí se hace notoria, como en ningún otro texto, la influencia dionisiana sobre la argumentación teológica de Buenaventura (190), sobre todo en lo que se refiere al excessus mentis (191).

La compenetración de razón y amor, entonces, alcanza su punto culminante, sin ser la última respuesta de Buenaventura al problema planteado, que involucra al amor en cuanto trascendental propiamente tal.

(188) Cf. las diferencias de las interpretaciones de los"sentidos espirituales", según K. RAHNER, Die Lehre von den "Geistlichen Sinnen" im Mittelalter, Schriften zur Theologie, XII, 1975, 137-172 y BALTHASAR H. Urs von, Buenaventura, en Gloria 2, Madrid 1986, 253- 342

(189) Itiner mentis VII, 4, Omnia Opera V, 312: In hoc autem transitu, si sit perfectus, oportet quod relinquantur omnes intellectuales operaciones, et apex affectus totus transferatur et transformetur in Deum. Hoc autem est mysticum et secretissimum, quod nemo novit, nisi qui accipit, nec accipit nisi qui desiderat, nec desiderat nisi quem ignis Spiritus sancti medullitus inflammat, quem Christus misit in terram. Et ideo dicit Apostolus, hanc mysticam sapientiam esse per Spiritum sanctum revelatam. Cf. Itiner mentis VII, 6 Omnia Opera V, 313: Si autem quaeras, quomodo hace fiant, interroga gratiam, non doctrinam; desiderium, non intellectum; gemitum orationis, non studium lectionis; sponsum, non magistrum; Deum, non hominem; caliginem, non claritatem; non lucem, sed ignem totaliter inflammantem et in Deum excessivis unctionibus et ardentissimis affectionibus transferentem. Qui quidem ignis Deus est, et huius caminus est in Jerusalem et Christus hunc accendit in fervore suae ardentissimae passionis, quem solus ille vere percipit, qui dicit: Suspendiam elegit anima mea, et mortem ossa mea. Quam mortem qui diligit videre potest Deum, quia indubitanter verum est: Non videbit me homo et vivet. Moriamur igitur et ingrediamur in caliginem, imponamus silentium sollicitudinibus, concupiscentiis et phantasmatibus; transcamus cum Christo crucifixo ex boc mundo ad Patrem ut, ostenso nobis Patre, dicamus cum Philippo: Stifficit nobis; audiamus cum Paulo: Sufficit tibi gracia mea; exsultemus cum David dicentes: Defecit caro mea et cor meum, Deus cordis mei et pars mea Deus in aeternam. Benedictus Dominus in aeternum et dicet omnis populus: Fiat, ...

(190) Itiner mentis VII, 5 Omnia Opera V, 312: Quoniam igitur ad hoc nihil potest natura, modicum potest industria, parum est dandum inquisitioni, et multum unctioni; parum dandum est linguae, et plurimum internae laetitiae; parum dandum est verbo et scripto, et totum Dei dono, scilicet Spiritui sancto; parum aut nihil dandum est creaturae, et totum creatrici essentiae, Patri el Filio et Spiritui sancto, dicendo cum Dionysios ad Deum Trinitatem: "Trinitas superessentialis et superdeus et superoptime Christianorum inspector theosophiae, dirrige nos in mysticorum eloquiorurn superincognitum et superlucentem et sublimissimum verticem; ubi nova et absoluta et inconversibilia theologiae mysteria secundum superlucentem absconduntur occulte docentis silentii caliginem in obscurissimo, quod est supermanifestissimum, supersplendentem, et in qua omne relucet, et invisibilium superbonorum splendoribus superimplentem invisibiles intellectus". Cf. BEIERWALTES W., Dionysius und Bonaventura, en ANDIA de Y., Denys 1' Aréopagite et sa posterité en Orient et en Occident, Paris 1996, 487-99; RATZINGER J., La théologie de l’histoire de saint Bonaventure, Paris 1988, 100-104: sostiene el autor, que la influencia de Dionisio sobre Bonaventura requiere una monografía especial.

(191) Idem, Omnia Opera V, 313 Hoc ad Deum. Ad amicum autem, qui haec scribuntur, dicatur cum eodem: "Tu autem, o amice, circa mysticas visiones, corroborato itinere, et sensus desere et 
c) El Amor, el trascendental como tal, según "Hex "I, 13; 14; IX, 2.

Si la argumentación teológica de Buenaventura en Hex se esclarece, fundamentalmente, a la luz del triple testimonio de la "verdad expresada por el Verbo increado", el "Verbo encarnado" y el "Verbo inspirado" (192). Hex I, 13 aporta una valiosa precisión para la comprensión del problema razón y amor, cuando afirma: "Porque el Padre engendró desde la eternidad al Hijo semejante a sí, y se dijo a sí mismo y dijo su similitud semejante a sí, y con ello todo su poder; dijo las cosas que podría hacer, y máxime las que quiso hacer, y las expresó todas en él, esto es, en el Hijo o en este medio, como en su arte" (193). Esto significa que el Hijo es "necesariamente el medio de las personas" -según Hex 1, 14-, de lo cual se deduce, que el Hijo es el exemplar exprimens (194), "porque el Verbo expresa tanto al Padre, como a sí mismo, como al Espíritu Santo y todas las demás cosas", según Hex IX, 2 (195).

De este modo, en el Hijo se expresa el Espíritu Santo, en la medida en que el Padre da al Hijo también el poder de espirarlo junto con Él. Esto es un hecho de un alcance imponderable. En la espiración del Espíritu por el Hijo se demuestra que "toda la plenitud de la divinidad" llega al Hijo (identidad del Padre y del Hijo como dador y don), y que el Hijo la "tiene en sí mismo" (diferencia entre Padre e Hijo como dador y don). Con otras palabras: en la espiración del Espíritu por el Hijo se muestra que el Padre se comunica, de modo perfecto, porque genera el origen "Hijo" igual a Él. Esta profundidad, donde arraiga, en definitiva, la diferencia entre dador y don merece plena atención, pues no ha sido tomada suficientemente en cuenta (196).

Si a nivel humano los padres fomentan la autonomía de su hijo, entonces la libertad de este se demuestra en la salida de la casa paterna para llevar una vida propia y aceptar la responsabilidad sobre otros. La separación de los padres significa, entonces, que padres e hijos se encuentran libres para una relación nueva y más profunda.

intelectuales operaciones et sensibilia et invisibilia et omne non ens et ens, et ad unitatern, ut possibile est, inscius restituere ipsius, qui est super omnem essentiam et scientiam. Etenim te ipso et omnibus immensurabili et absoluto purae mentis excessu, ad superessentialem divinarum tenebrarum radium, omnia deserens et ab omnibus absolutos, ascendes"

(192) Cf. Hex I, 11- 38 Omnia Opera V, 331-335; Hex IX, 1 Omnia Opera V, 372: Et ideo intelligendum, quod huius fidei firmitas est triplex. Prima est ex testimonio veritatis expressae per Verbum increatum; secundum, ex testimonio veritatis expressae per Verbum incarnatum; tertia, ex testimonio veritatis expressae per Verbum inspiratum.

(193) Hex I 13, Omnia Opera V, 331: Pater enim ab aeterno genuit Filium similem sibi et dixit se et similitudinem suam similem sibi et cum hoc totum posse suum; dixit quae posset facere, et maxime quae voluit facere, et omnia in eo expressit, siciliect in Filio seu in isto medio tanquam in sua arte. Unde illud medium veritas est;

(194) Hex I 14, Omnia Opera V, 314s: Istud est medium personarum necessario: quia, si persona est, quae producit et non producitur, et persona, quae producitur et non producit, necessario est media quae producitur et producit. Haec est ergo veritas sola mente perceptibilis...

(195) Hex IX, 2 Omnia Opera V, 372s: A tribus datur testimonium, sed exprimitur per Verbum, quia Verbum et Patrem et se ipsum et Spiritum sanctum exprimit et omnia alia. Cf. In I sent d. 32, Omnia Opera I, 558: Pater et Filius diligunt se Spiritu Sancto, hoc est, invicem concordando spirant Spiritum sanctum, vel spirando Spiritum Sanctum invicem connectuntur.

(196) BIELER M, Karl Barths Auseinandersetzung mit der Analogía entis und der Anfang der Theologie, CATH 40(1986) 229-245. 
De modo semejante, el Hijo acepta la separación del Padre; al espirar al Espíritu en continuidad con el movimiento de salida del Padre, llega a ser el mismo origen y trasciende hacia el Padre en la comunicación de sí mismo al Espíritu. En la aparente alienación del Origen primordial, el Hijo permanece unido a Él y vuelve a Él, de tal modo que junto con el Padre espira al Espíritu. Egreso y regreso no son fases sucesivas separables en el Hijo, ya que el movimiento del egreso se realiza como regreso.

Lo dicho es posible de ejemplificar con la imagen del movimiento circular. Mientras el lugar del Padre es el punto culminante del círculo trinitario, del cual procede todo el acontecer y al cual vuelve, el Hijo representa el punto crucial más bajo de tal movimiento circular, en el cual se interrelacionan egreso y regreso, con lo que se logra la unidad. Para completar la imagen debe imaginarse al Espíritu como centro del círculo, que "recién" brota del movimiento del Padre e Hijo, movimiento que cierra el círculo en torno al cual siempre todo se mueve como preocupación común del Padre e Hijo. Los tres puntos fijos ejemplifican dos cosas: en el movimiento circular de la vida trinitaria no confluye todo de modo indiferenciado, sino que se realiza según un orden fijo.

En tal orden, al Hijo corresponde el centro -es "persona media"-. El centro es a la vez comienzo, porque el Hijo se encuentra ante el Padre como el que comienza, y ante el Espíritu como el que debe comenzar. Sin Espíritu el Hijo no sería centro, de tal modo que el Padre con el Hijo ya está con el Espíritu y expresa todo junto con el Hijo. Esto significa que Dios -gracias al Hijo-, recién es capaz de proyectarse en un otro subsistente. En el Hijo, Dios se puede comunicar de tal modo que del primer origen brota otro origen, en el cual también está puesto el "tercero". Precisamente la doble connotación de este encontrarse puesto, es decir, de ser expresión pasiva, dentro de la cual también el Espíritu y todo lo demás está contenido, y de ser igualmente autoexpresión (del Espíritu, etc.), el Hijo es el "arte de Dios", por el cual todo es creado, según Hex I 13, de tal modo que el Hijo no es una copia sin vida, ni sirve de simple modelo Hex I, 14.

Para comenzar con algo más universal, corresponde aventurarse con una pregunta como la siguiente: ¿cómo se refleja el ser absoluto de Dios en el ser creado, ya que Aquel solo puede ser trinitario, pese a que las obras ad extra (si esto existe) son realizadas en común? Hay que preguntar seriamente por la imago trinitatis en el ente creado, aunque no se haya planteado esta pregunta con frecuencia en la historia de la Teología (197). Esta pregunta se dejó de lado parcialmente, pues cuando no se preguntó en primer lugar por la relación entre la diferencia trinitaria y la diferencia del ser en el ser mundano, sino por las características generales del ser -los trascendentales-, se quiso saber de qué manera estos penetran en forma supracategorial el ser, pudiendo ser predicados del ser divino y mundano.

Si Buenaventura aplica los trascendentales a Dios y al Padre, Hijo y Espíritu Santo, estas apropiaciones explican una triple relación del ser creado con el ser divino a través de los trascendentales: "pues toda criatura se constituye en el ser por una causa eficiente, se conforma a un modelo y se ordena a un fin; y así viene a ser una, verdadera y buena". Sin embargo, no se puede aplicar los trascendentales ex-

(197) BALTHASAR H.U., Teodramática 5, Madrid 1997, 64-65. 
clusivamente a la divinidad como tal. En cuanto Imago y ejemplaridad de todo lo creado, este es nombre propio del Hijo; como la liberalidad y fundamento, porque la creación es real, Don es nombre propio del Espíritu Santo.

Aunque la encarnación del ser mundano es común, cada uno actúa según su propiedad, y puesto que es propiedad del Espíritu ese desborde del amor que realiza la creación, surge la pregunta: visto desde el ser de Dios, ¿puede este último momento que determina la existencia del ser mundano ser considerado lo primero in intentione de la procesiones intradivinas? Si bien es cierto que los trascendentales penetran todo ser, sin embargo, la realidad subespiritual alcanza recién su plenitud allí donde el ser se ilumina en el ser espíritu; y, si es cierto que el amor perfecto presupone también el conocimiento perfecto, la "expropiación" del Padre respecto del Hijo se debe a un amor que trasciende todo ser y autoconocimiento.

El amor como tal, entonces, es más abarcante que el ser mismo -el trascendental como tal-, que sintetiza la realidad del ser, de la verdad y de la bondad. El amor es la profundidad del ser bueno, y abarca la existencia y el ser verdadero. Así también lo bueno es más trascendental que el ser y lo verdadero, y como tal, surge desde la última profundidad del sumo ser, que como bonum llega a su verdadera esencia. La demostración decisiva de esta afirmación es el Hijo, que si no es acogido en el espacio del amor paterno nunca llega a ser hombre. Por el amor a la comprensión el Hijo llega antes al conocimiento; con el despertar del corazón, llegan al mismo tiempo y en el mismo acto la razón espiritual y la voluntad espiritual a su plena actividad connatural.

En síntesis, si se reflexiona nuevamente sobre el proceso de las procesiones íntimas de Dios, no se pueden recorrer ambos caminos: 1) el de un Padre que engendra al Hijo para reconocerse como Dios; y 2) el de un Padre que se conoce perfectamente y por eso engendra al Hijo. Ello nos lleva a concluir que la entrega del Padre que le hace ser Padre no puede ser el conocimiento, sino solo el amor sin fondo, que es el trascendental como tal.

\section{d) La visión beatífica, contemplación de la hermosura de Dios, según "Soliloquium "I 3. 4.(=Soliloq)}

Para Buenaventura la compenetración razón y amor alcanza su articulación perfecta en la desproporción de esta vida y la vida eterna, que describe Soliloq I, 3 y 4 . Sintetiza todo su esfuerzo por comprender la Trinidad y su imagen en el hombre a través de la apropiación de los trascendentales (198).

Sin duda, emerge el conocimiento traspasado por la diferencia siempre mayor, pues "cuán incomprensible" es; el deseo por la hermosura, "cuán deseable", y la admiración "cuán admirable" (199).

(198) Soliloq I 3, Opera Omnia, VIII, 30: Primo ergo considera, quam generose formata sis per naturam. Generositas tua naturalis consistit in hoc, ut existimo, quia tibi naturaliter ad tui decorem impressa est imago beatissimae Trinitatis.

(199) Soliloq I, 3, Opera Omnia, VIII, 30: ...quantum in creaturis omnibus admirabilis, quia omnia potenter creat, sapienter gubernat, benigne dispensat... -Reconosce ergo, o anima mea, quam mira et inaestimabilis dignitas est, esse non solum vestigium Creatoris, quod est commune omnibus creaturis, sed etiam esse imaginem eius, quod est proprium creaturae rationalis. 
Finalmente, la argumentación se detiene en la visión beatífica, la contemplación de la hermosura de Dios, donde razón y amor coexisten en una reciprocidad dinámica, pues no solo el alma tiende hacia la hermosura de Dios, sino que es ella quien descubre su hermosura propia gracias al Esposo, cuya mirada queda prendado en ella para siempre (200).

Sin duda, el presente texto sintetiza vivamente, a la luz de la confluencia de fuentes griega y latinas, la compenetración de la razón y el amor a través de la belleza, tanto infinita como finita.

Sintetizando, para Buenaventura los trascendentales revelan la perijóresis personal en cuanto compenetración de cada una de las tres personas divinas que $S e$ manifiesta, Se da, Se dice (201). Estos trascendentales aparecen mencionados, tan solo, esporádicamente por los autores anteriores, sin sistematización, ni aplicación a la Trinidad. Por lo cual, lo fascinante y a la vez frágil del aporte de Ricardo a la solución del problema razón y amor, recibe un arraigo en el ser, que se concreta en la relación, siendo la perijóresis del Padre Hijo y Espíritu Santo el fundamento último y personal del hecho que razón y amor se compenetren, teniendo su concreción definitiva en el Hijo en cuanto "persona media" (202). Por lo cual, el aporte pneumatológico de Ricardo adquiere aquí su real consistencia cristológica y explicitación definitiva, aproximándose con ello llamativamente a lo aportado por Guillermo de St. Thierry.

Dichos vestigios del ser, en efecto, explican la dinámica que se da entre la revelación y el ocultamiento, que adquiere en Buenaventura una especial densidad en cuanto especulación y enigma yque se concentra en la hermosa reciprocidad nupcial, de la cual da cuenta, de modo elocuente, la cita agustiniana. Como tales, sintetizan magistralmente, no solo la confluencia de las fuentes latinas y griegas, sino que atestiguan, además, la índole propia de los trascendentales en cuanto concreción del nexo misterioso entre lo individual y lo colectivo. La compenetración de razón y amor resalta con mayor claridad a partir de la Trinidad inmanente, pero, sin duda, a nivel creatural dicha compenetración se realiza en cuanto analogía proporcional, es decir, los extremos opuestos se unen para una novedad cada vez mayor. De este modo, la semejanza de la imagen con la Trinidad se articula desde una mayor desemejanza: la distinción intratrinitaria entre el don y el dador.

(200) Soliloq I, 4 Opera Omnia, VIII, 30-31: Sed quia haec modica non immerito forte indicarentur, si morte finirentur; exulta et lauda, quia cum praedictis dedit tibi naturam immortalem, substantiam incorruptibilem, durationem interminabilem, vitam perpetuam... y continua con san Agustín: O anima, adverte, quod Creator tuus post illud esse dedit tibi pulcrum esse, dedit tibi perpetuum esse, deditque tibi vivere, sentir, discerne, sensibus te decoravit, sapientia illustravit". "Tuam igitur pulcritudinem attende, ut intelligas, qualem debeas pulcritudinem diligere. Quodsi temetipsam, ut expedit, contemplari non sufficis, cur saltem, quid de te aestimare debeas, ex iudicio alieno non perpendis? Sponsum habes, de cuius pulcritudine, si dubitares, scire posses, quod tam pulcher, tam formosus, tam unicus Dei Filius tuo aspectu captus non esset, si eum singularis decor tuus et ultra ceteros admirandus non traxisset" Haec Augustinus.

(201) Para las implicaciones prácticas cf. HEINZ H., Trinitarische Begegnungen bei Bonaventura.Fruchtbarkeit einer appropriativen Trinitätstheologie (Beiträge zur Geschichte der Philophie und Theologie des Mittelalters Neue Folge, 26) Münster 1985, 291-94.

(202) Cf. SCHLOSSER M., Einleitung, Bonaventura de Triplici Via. Über den dreifachen Weg (FONTES CHRISTIANI, 14) Freiburg, Basel, Wien, Barcelona, Roma, New York 1993, 62-65. La influencia de Ricardo sobre Bonaventura, en general, se considera mínima. Cf. GONZALEZ O., o. c. 


\section{A MODO DE CONCLUSIÓN}

Al finalizar el extenso recorrido a través de siete autores medievales en busca de una solución al problema de razón y amor, podemos constatar con sorpresa, que hemos llegado más lejos de lo que nos habíamos propuesto. Resulta evidente que en todo momento del complicado hilamiento de ideas, precisiones y matices, la razón queda idéntica a sí misma como una capacidad natural, activa y destacada del ser humano para aprehender y esclarecer todo aquello que se le presenta por delante, aunque condicionada a lo que los sentidos le ofrecen y sobrepasada a veces por la inteligencia, pero apoyada en la gracia, de tal modo, que, con acierto, puede hablarse del "carisma de la racionalidad". El amor, por su parte, se muestra esquivo a cualquier definición en cuanto auténtico fenómeno originario. No puede definirse, pero conlleva diversas facetas muy cercanas al desiderium, propio del eros, la intencionalidad y afectividad, para alcanzar su máxima expresión en la amistad, o mejor dicho, en la con-dilectio. De todos modos, no hay duda que el amor anticipa a la razón, la envuelve y sostiene como condición de posibilidad. De ahí resalta aquella compenetración de ambas realidades, atestiguada por todos los autores, en cuanto prioridad del amor con respecto a la razón, pese a que Eriúgena pone el acento en la razón. Esta compenetración se gesta, en forma acentuada, a partir de la interrelación entre el planteamiento teológico propio de cada autor y su comprensión del amor y de la razón.

En efecto, el problema razón y amor emerge condicionado a la forma mentis de los autores, la que depende del uso de la S.E. y de las fuentes. Al actuar así, estos autores crean su propia sistematización teológica, integrando el problema del amor y de la razón en su "sistema" propio, para darle una respuesta, orientada, en gran parte, por el complejo acondicionamiento del contexto. Sucede así con la exégesis alegórica de Gregorio Magno, orientada desde el intus-foris por la práxis coherente de la caridad en cuanto amistad, lo mismo que con la systembildende Alegorese de Ricardo de San Víctor. Esto también vale para la articulación del problema en Eriúgena y Anselmo a partir del sola ratione, hasta las imponentes visiones proféticas de Hildegard, con su simbolismo apocalíptico de fuerte racionalidad, designada por ella misma "ignea" y "ardiente". En cuanto estructura mental, tal racionalidad se aprecia, sobre todo, en los aportes propios de Guillermo, el "teólogo del amor" por excelencia, quien elabora las facetas nítidas de la solución del problema desde su propia experiencia. Ricardo y Buenaventura, finalmente, sistematizan y profundizan los aportes anteriores con maestría, y les dan aquella expresión refinada, que remonta, en definitiva, hasta la originalidad que adquieren las fuentes latinas y griegas en su pensamiento.

Las fuentes confluyen, sin duda, para una mayor originalidad, pero no de tal modo, como si Agustín, encabezando los latinos, hubiera acentuado el primado del amor sobre la razón, ya que esto constituye el aporte de Dionisio, tan omnipresente como Agustín en el período estudiado, aunque anticipado por lo que Gregorio de Nisa logra dilucidar del problema. En efecto, desde los primeros atisbos en Gregorio Magno hasta la cita explícita del Soloq de Buenaventura, el obispo de Hipona aporta a la comprensión del problema razón y amor la nitidez e índole personal, de tal modo que la razón ejerce su ser imagen de Dios y el amor, más que deseo e impulso -Gregorio 
de Nisa- es apreciado en cuanto amicitia Dei, dilectio y caritas. Tal esfuerzo por darle rostro a la intelección de la razón y el amor, se percibe también a través de la influencia agustiniana sobre Anselmo y Guillermo, mientras Eriúgena como Hildegard y Ricardo argumentan, preferentemente, sobre el trasfondo dionisiano, que los conduce a una mayor profundidad, más allá del ser concreto, y a una comprensión supraesencial del ser, que sin embargo significa pérdida de la subsistencia creatural. En estos últimos autores, el amor parece encontrarse condicionado al racionamiento, como lo atestigua, sobre todo, Eriúgena, pese a que, de facto, conserva su prioridad, mientras Buenaventura parece que logra equilibrar, con mayor acierto, la confluencia de las fuentes en lo que se refiere a la compenetración de razón y el amor. Tal equilibrio se articula a través de una llamativa acentuación del ocultamiento que traspasa tanto la racionalidad como el amor, y como tal es a la vez revelación.

De hecho, la revelación y el ocultamiento expresan, de manera significativa, la compenetración del amor y la razón, no solo a modo de los dos querubines, colocados encima del arca en el BenMay de Ricardo, sino, sobre todo, a través del símbolo del fuego, al cual recurren todos los autores como testimonio vivo de la presencia divina, que, permaneciendo oscuridad, a la vez se revela como luz. Designación expresa, donde la razón se encuentra en el amor y viceversa, mas siempre hecho referido a Dios, de tal modo, que ella apunta a la similitud, que constituye su ámbito propio. Pese a todo, la razón no se proyecta, primordialmente, a través de una atribución óntica, analogia entis, en su relación con la verdad, sino que se realiza como un asemejarse radical y desproporcionado, que solo puede llevar a cabo la voluntad, es decir, el amor. Esto explica la índole práctica de la verdad, que descubrimos en todos los autores desde Gregorio Magno, sobre todo en Anselmo y Ricardo, y también el permanente magis del amor con respecto de la razón.

De todos modos, la mayor disimilitud no se comprende sino per aliud, dice Anselmo. Enfatiza aquella subsistencia amenazada en Eriúgena. Este pensador permite en su planteamiento del problema razón y amor, que el Espíritu de Dios ocupe el lugar del espíritu creado, subsistencia, entonces, que le es propia en cuanto criatura racional a imagen de Dios. El intus de Gregorio Magno se refuerza por la entrada del espíritu en sí mismo y el descubrirse el hombre imagen de Dios, a través de las potencias de su espiritu-alma, que recuerda, conoce y ama, como permiten apreciar, sobre todo, Anselmo y Ricardo. Buenaventura, sin duda, completa estos esfuerzos por apropriar la unidad, verdad y bondad, aquellos vestigios del ser, a la Trinidad, de tal modo, que la compenetración del ser y de la persona garantizan la índole relacional del problema amor y razón.

Pero previamente a que Ricardo y Buenaventura lleven dichos aportes a una elaboración casi definitiva y exclusivamente trinitaria del problema, prolongando a Gregorio Magno, Guillermo insiste en la impotencia del amor defectuoso, que remonta a la dimensión kenótica de la Encarnación. La Encarnación, pues, abre la racionalidad del amor en su dimensión "sentida", es decir, la delimita por los sentidos. Estos, no solo aportan, para Hildegard, la abertura, la puerta, al mundo y su exuberante plenitud-verdor-, sino en Guillermo, Ricardo y Buenaventura logran también revertir la pasividad aparentemente negativa, por una receptividad salvífica, proveniente del amor extremo, tal como lo atestiguan los "sentimientos de Cristo"Flp 2, 5s-. El "sentir con Cristo", aporta, pues, una inteligencia al problema razón y 
amor, que transforma los sentidos en "sentidos espirituales", en cuanto afectan tanto la razón como el amor y llevan a Guillermo y Ricardo a hablar del sensus amoris y de la "razón sentida", un"medium" entre razón y amor.

La dimensión kenótica de la compenetración del amor y de la razón, proveniente de la Encarnación, remonta, sin embargo, en definitiva, a la Trinidad inmanente, como Ricardo de San Víctor lo señala magistralmente cuando, retomando una fórmula feliz de Gregorio Magno, demuestra que "la caridad solo es posible entre dos", es decir, requiere del "otro". Este "otro", a su vez, remite a un "tercero" quien en cuanto con-dilector, es el Espíritu Santo. La identidad de este Espíritu consiste en "poseer nada para sí”. De este modo, pasa a constituirse en el Amor por autonomasia, amor este que, junto al amor del Padre y el del Hijo, posee su mismidad de Espíritu en no tener nada.

La solución trinitaria al problema razón y amor, con su punto culminante en Ricardo de San Víctor, es indudablemente la más acertada de todo lo que hemos encontrado en la presente investigación y la más decisiva, en lo referente a que el problema razón y amor tiene que ver con el Espíritu Santo, aunque no definitiva. Pero a su vez no confirma la definitiva. Pues sí el Hijo y no el Espíritu es "la persona media", como argumenta Buenaventura, mediante su inaudita adjudicación de los trascendentales a la Trinidad, esto no solo asegura la reciprocidad, fundamental para la compenetración del amor y la razón, sino también la espontaneidad de la receptividad. Ello pone de relieve el nexo misterioso que existe entre lo individual y lo colectivo, de tal modo que la singularidad en su belleza, se confirma en su mismidad desde el "otro", desde esta mirada recibida del Unico, quien es a la vez razón y amor en cuanto persona, desde siempre y para siempre.

\section{RESUMEN}

El presente estudio escoje un período de gran envergadura teológica y excepcionalmente sensible al problema razón y amor. En el siglo XII se va gestando la subjetividad moderna, de tanta relevancia para la Teología, pero, sobre todo, se produce aquella confluencia de fuentes latinas y griegas, que como problema requiere máxima atención, ya que su recepción patrística medieval es vital para la búsqueda de la verdad a través de la ciencia. Se estudian siete autores que remontan al siglo XII: -Hildegard von Bingen, Guillermo de St. Thierry, Ricardo de San Víctor-, pero tres le preceden: -Gregorio Magno, Juan Escoto Eriúgena, Anselmo de Canterbury- y uno los complementa: Buenaventura. La elección de estos autores ha permitido seguir de cerca la articulación del problema, su contextualización y las soluciones novedosas, de gran riqueza antropológica teológica.

\section{ABSTRACT}

This study selects a period of great theological depth and particularty sensitive to the issue of reason and love. The modern subjectivity, which has had enormous relevance for Theology, started to germinate during the XII century; the times of the convergence of the Latin and Greek sources. This required much attention, as their reception by the medieval patristic is essential for a proper search of the truth through the science. The article focuses on seven authors who date from the XII century. Hildegard von Binger, Willian of St. Thierry, Richard of Saint Victor, who are preceded by Gregory the Greta, John Scotus Eriungena, Anselm of Canterbury and Bonaventure. The selecction of these authors allows a close articulation of the problem, its contextualisation and novel solutions of great theological and anthropological richness. 